\title{
Combustion Synthesis of Ceramic Powders with Controlled Grain Morphologies
}

\author{
Guanghua Liu ${ }^{1}$, Jiangtao $\mathrm{Li}^{1}$ and Kexin Chen ${ }^{2}$ \\ ${ }^{1}$ Technical Institute of Physics and Chemistry, Chinese Academy of Sciences, Beijing \\ ${ }^{2}$ Department of Materials Science and Engineering, Tsinghua University, Beijing \\ China
}

\section{Introduction}

Combustion synthesis, which is also known as self-propagating high-temperature synthesis (SHS), is a facile and economic technique to prepare a large variety of advanced materials, such as ceramics, intermetallics, composites, and functionally-graded materials [1-4]. By this technique, new materials are synthesized from self-sustained exothermic chemical reactions instead of long-time heat treatment by furnace. Once the reactants are ignited, a large amount of heat energy is produced to support the reaction to continue. With the propagation of combustion wave through the whole sample, the reactants are converted into products. Because exothermic combustion reactions occur quickly, a non-equilibrium state is usually involved in combustion synthesis and characterized by high temperatures and fast heating or cooling rates. This non-equilibrium reaction state offers an opportunity for controlling the microstructure of products.

Among the extensive applications of combustion synthesis, the fabrication of advanced ceramic powders is an important and successful practice. By combustion synthesis, many kinds of ceramic powders have been prepared, including nitrides $\left(\mathrm{Si}_{3} \mathrm{~N}_{4}, \mathrm{AlN}, \mathrm{TiN}, \mathrm{BN}\right.$, SiAlON, etc.), carbides ( $\mathrm{SiC}, \mathrm{TiC}, \mathrm{ZrC}, \mathrm{Ti}_{3} \mathrm{SiC}_{2}, \mathrm{Ti}_{3} \mathrm{AlC}_{2}, \mathrm{Ti}_{2} \mathrm{AlC}$, etc.), borides $\left(\mathrm{MgB}_{2}, \mathrm{TiB}_{2}\right.$, $\mathrm{ZrB}_{2}$, etc.), silicides (e.g. $\mathrm{MoSi}_{2}$ ), and oxides (e.g. ferrites, Y-Ba-Cu-O superconductors). The grain size and morphology of the ceramic powders can be manipulated by controlling the processing parameters, such as proportion of diluents, porosity of green compacts, and particle size distribution of raw materials.

This chapter presents some recent results on combustion synthesis of ceramic powders, with an emphasis on the investigation of crystal growth kinetics and control of final grain morphologies. Four kinds of ceramic powders (TiN, SiC, SiAlON, and Ti-Al-C) with different grain morphologies are reported as examples. The grain growth mechanisms involved in combustion synthesis of these ceramic powders are discussed in detail.

\section{Combustion synthesis of TiN powders with different grain morphologies}

The nitrides of transition metals have received increasing attention because of their unique chemical and physical properties. Among these materials, TiN is particularly interesting due to its superior hardness, good thermal stability, high wear resistance, excellent corrosion resistance, and relatively high electrical conductivity [5]. It can be used as a coating material 
on cutting tools, diffusion barrier in microelectronic devices, and protective layer on optical components. For these various applications, the surface roughness, film texture, and crystallization shape of TiN strongly affect its physical properties. Therefore, it is important to understand the nucleation and growth kinetics of TiN for controlling its microstructure. In this aspect, many results have been reported on the epitaxial growth of TiN thin films. In the preparation of TiN powders or bulk ceramics, however, studies on the crystal growth and shape evolution are limited.

Combustion synthesis is an important method to prepare TiN powders. This method can induce high reaction temperature and drastic heating or cooling rate, which offers an opportunity to manipulate the microstructure of the products. By controlling the starting compositions and processing parameters in combustion synthesis, TiN powders can be prepared with different grain morphologies [6].

Using commercial Ti powder (99\% pure, 300 mesh, General Research Institute for Nonferrous Metals, Beijing, China) and high-purity $\mathrm{N}_{2}$ (99.9 \%, Huayuan Gaseous Co., Beijing, China) as major reactants, $\mathrm{TiN}$ and $\mathrm{NH}_{4} \mathrm{Cl}$ as additives, single-phase TiN can be prepared by combustion synthesis. As shown in Figure 1, no residual Ti or other impurity is detected in the product, indicating that the Ti powder has been fully nitridized into TiN. Figure 2 shows the temperature history during the combustion reaction. It is clear that, once the combustion reaction is triggered, the temperature immediately increases from room temperature to nearly $2000^{\circ} \mathrm{C}$ in only one second, and the maximum heating rate reaches $6000^{\circ} \mathrm{C} / \mathrm{s}$. When the combustion reaction is over, the sample quickly cools down with a cooling rate of $\sim 60^{\circ} \mathrm{C} / \mathrm{s}$. In the short reaction period, the resultant TiN micro-crystals undergo a fast shape evolution process and develop into various morphologies such as quasi-spherical grains, faceted cubic or pyramidal crystals, and dendrites, as shown in Figure 3.

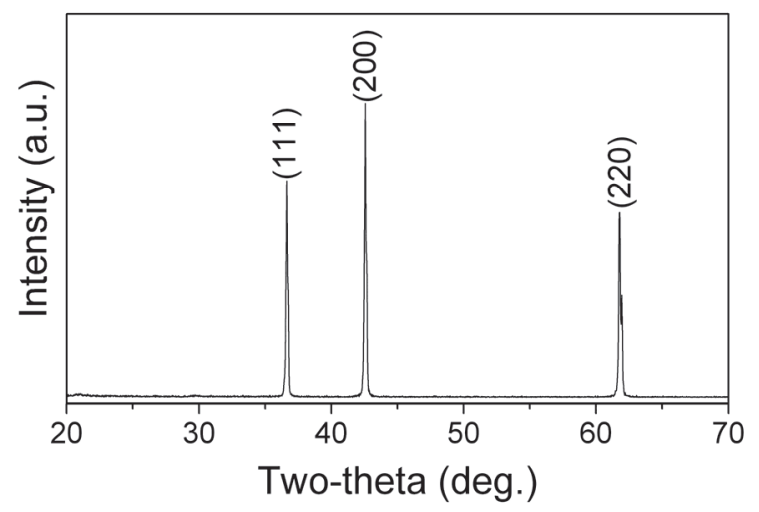

Fig. 1. XRD pattern of TiN powder prepared by combustion synthesis

Generally speaking, the final morphology of a crystal depends on both its intrinsic lattice structure and external conditions for growth. The intrinsic lattice will lead to the equilibrium crystal shape (ECS) with minimum total surface energy, and the external conditions often force the crystal to deflect from its ECS and develop into various morphologies. The actual crystal shape is derived from the competition of internal and external factors. Based on this viewpoint, the formation mechanisms of the observed different morphologies of TiN grains can be discussed. 


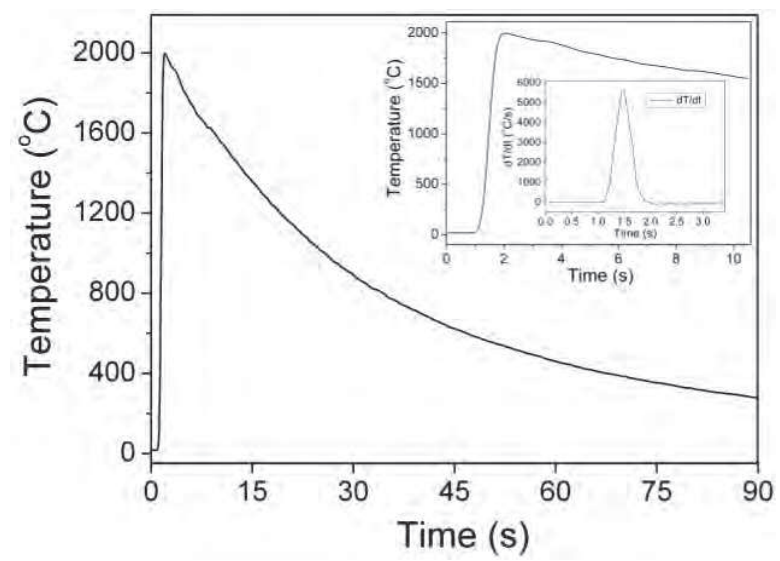

Fig. 2. Temperature history during the combustion synthesis of TiN

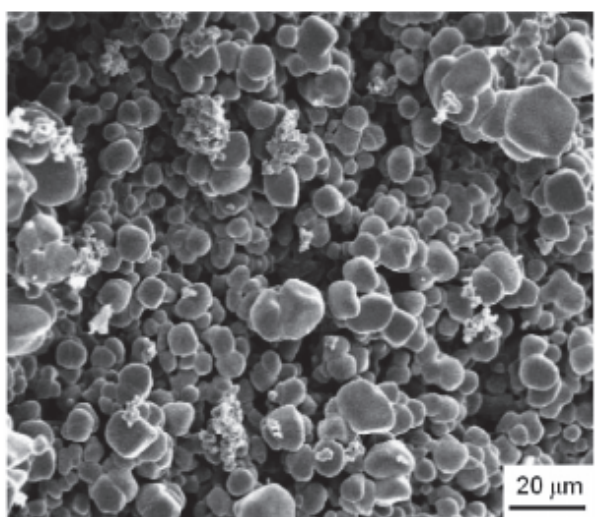

(a)

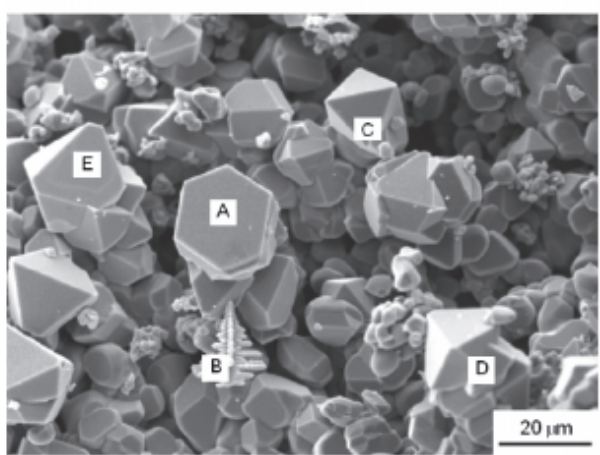

(c)

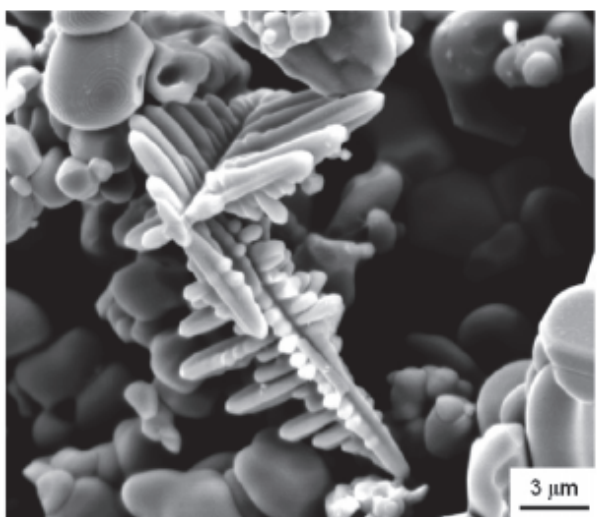

(b)

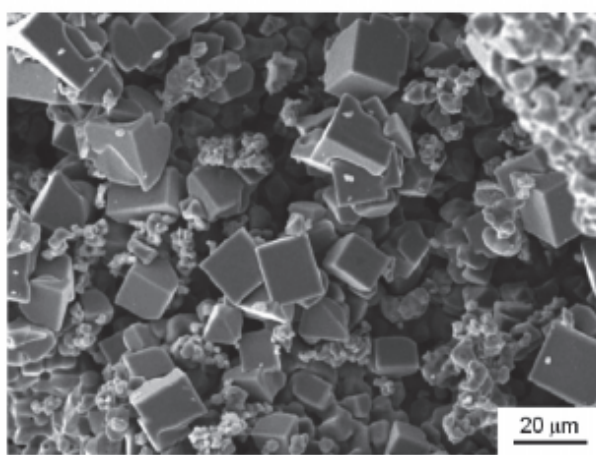

(d)

Fig. 3. TiN powders prepared by combustion synthesis with various grain morphologies: (a) quasi-spherical grains; (b) dendrites; (c) faceted pyramidal crystals; (d) faceted cubic crystals 


\subsection{Quasi-spherical TiN grains}

In the combustion synthesis of $\mathrm{TiN}$, the maximum reaction temperature (Figure 2) is much higher than the melting point of Ti. Therefore, in the combustion reaction, $\mathrm{TiN}$ is produced mostly by the reaction between $\mathrm{Ti}$ melt and $\mathrm{N}_{2}$. Compared with the gaseous reaction of $\mathrm{Ti}$ vapor and $\mathrm{N}_{2}$, the nitridation of Ti melt has a lower latent enthalpy. In this case, the interface between TiN crystals and Ti melt is thought to be rough and there is no crucial nucleation barrier for the formation of TiN. That is to say, new TiN nuclei can be formed continuously, which then grow isotropically into quasi-spherical grains.

Figure 4 simply illustrates the continuous growth of the quasi-spherical TiN grains. In the $\mathrm{N}_{2}$ atmosphere at a high pressure, some $\mathrm{N}_{2}$ molecules or $\mathrm{N}$ atoms can dissolve into Ti melt and then react with the latter to produce initial TiN nuclei. These nuclei act as the bases for later heterogeneous nucleation, which is easier than homogeneous nucleation in Ti melt. By diffusion, the dissolved $\mathrm{N}_{2}$ molecules or $\mathrm{N}$ atoms move to the interface and react with Ti via the reaction of $\mathrm{Ti}($ melt $)+\mathrm{N}_{2} /[\mathrm{N}] \rightarrow \mathrm{TiN}$ (crystal). Because there is no crucial nucleation barrier, the formation and growth of TiN is limited by the diffusion of $\mathrm{N}_{2}$ or $[\mathrm{N}]$ in Ti melt.

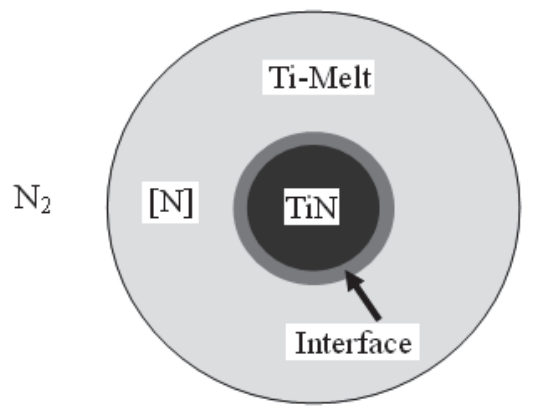

Fig. 4. A simple illustration of diffusion-controlled continuous growth of quasi-spherical TiN grains

\subsection{Faceted TiN crystals}

As mentioned above, crystals with anisotropic surface energy are inclined to reach the ECS with the minimum total surface energy. Generally, ECS is bounded with the close-packed faces with larger interplanar spacings because they have lower surface energy. Experimental observations have revealed that, the importance (frequency of occurrence) of a crystal face decreases with its interplanar spacing, which is known as the Bravais-Friedel law $[7,8]$. TiN has a composite face-centered cubic (FCC) lattice like $\mathrm{NaCl}$, and its crystal faces with decreasing interplanar spacings run as $\{100\},\{110\},\{111\},\{200\},\{220\},\{222\}$. In the composite FCC lattice of TiN, the elementary growth layers are $\{200\},\{220\}$ and $\{222\}$. According to the Bravais-Friedel law, the importance of these crystal faces should be $\{200\}>\{220\}>\{222\}$. If only the most important $\{200\}$ faces are exposed, the ECS of TiN should be a cube.

From kinetic point, crystal growth is such a process that the reactant atoms in fluid phases are attached and bonded at crystal surface. The attachment energy or bonding energy can be used to estimate the difficulty for the formation of a new layer. The crystal faces with higher bonding energies have higher growth rates, which will shrink gradually and finally disappear during crystal growth. On the contrary, the crystal faces with lower binding energies and growth rates will be reserved and exposed in the end. 
Now let's consider the binding energy for a new atom at $\{200\},\{220\}$, and $\{222\}$ faces in a TiN crystal according to the atom arrangements shown in Figure 5. Although TiN has a lattice structure like $\mathrm{NaCl}$, the bonding ways are different in these two compounds. It is usually accepted that, TiN is not a normal ionic-bonded compound like $\mathrm{NaCl}$, but a Hägg phase bonded with covalent and metallic bonds. The metallic bonds are formed among the $d$ electrons of $\mathrm{Ti}$, and the covalent bonds are formed between the $d$-electrons of Ti and the $p$ electrons of $\mathrm{N}$. The metallic bonds are relatively weak, while the directional covalent bonds are much stronger. In this way, the bonding energy is mainly determined by the covalent bonds between the new atom and its first nearest neighbors, with the distance of $a$. As shown in Figure 5, the number of first nearest neighbors of a new atom is 1, 2, and 3 for $\{200\},\{220\}$, and $\{222\}$ faces, respectively. Therefore, crystal faces with decreasing binding energies and thus growth rates run as $\{222\}>\{220\}>\{200\}$. During crystal growth, the crystal faces with higher growth rates will shrink and those with lower growth rates will expand. Therefore, in the final crystal shape, crystal faces with increasing importance should be $\{222\}<\{220\}<\{200\}$, which agrees well with the prediction from the Bravais-Friedel law.

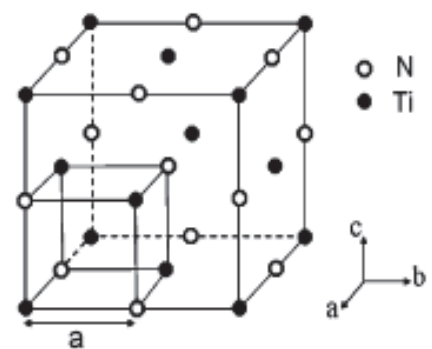

(a)

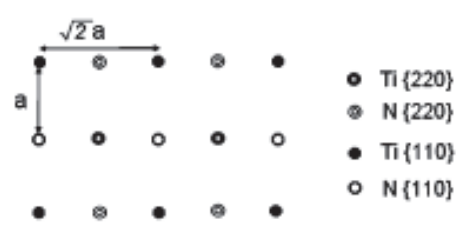

(c)

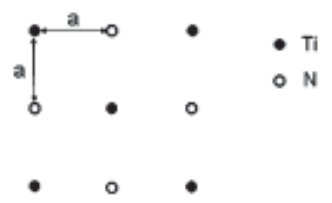

(b)

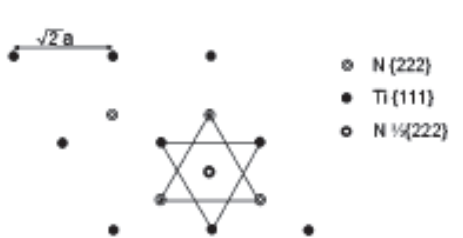

(d)

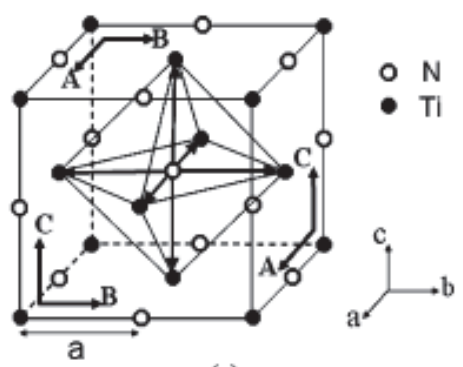

(e)

Fig. 5. A schematic illustration showing (a) the FCC lattice structure, (b), (c), and (d) atom arrangements at $\{200\},\{220\}$, and $\{222\}$ faces, and (e) PBC vectors in TiN crystals 
For the prediction of final crystallization shape of a crystal based on its intrinsic lattice structure, the Periodic Bond Chain (PBC) theory is usually considered. According to PBC theory $[7,8]$, a crystal should be bounded by edges parallel to the directions in which there is a continuous chain of strong bonds between the building units. Such a chain is called a PBC and the crystal can be considered as an array of PBCs. From the numbers of PBCs involved, crystal faces are divided into three categories, F-faces containing two or more PBCs, S-faces containing only one PBC, and K-faces containing no PBC. The three types of crystal faces have different growth rates, F-faces grow slowly and thus are important faces, K-faces grow fast and have least importance, and S-faces have a middle importance. In the lattice structure of TiN, there are three PBCs consisting of continuous strong Ti-N covalent bonds, viz. A/ $/ 100]$, $\mathrm{B} /[010]$, and $\mathrm{C} / / 001]$, as shown in Figure 5. Thus, $\{200\},\{220\}$, and $\{222\}$ faces are identified as F, S, and K-faces, respectively. Therefore, $\{200\}$ faces are most important and exposed, while $\{220\}$ and $\{222\}$ faces will shrink during crystal growth and finally degrade to edges and corners. By this means, faceted cubic TiN crystals are produced, as shown in Figure 6 (a).

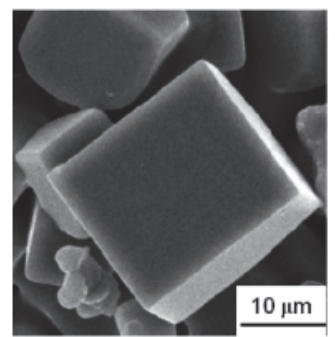

(a)

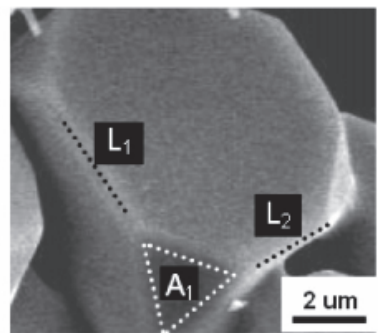

(b)

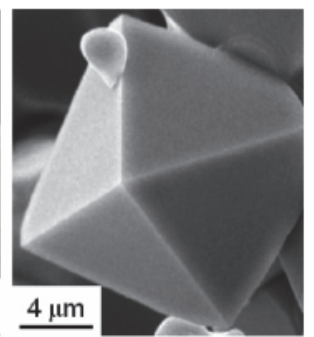

(c)

Fig. 6. Several typical shapes of faceted TiN crystals: (a) cube; (b) truncated cube; (c) pyramid

Except for the intrinsic factor, external conditions also affect the growth of TiN crystals and cause a deflection of crystal shape from the ECS. It is reported that, during the growth of TiN thin films, the preferred orientation of TiN crystals depends on the incident ion/metal flux ratio, and the nucleation kinetics of TiN is strongly affected by reaction temperature and the pressure of $\mathrm{N}_{2}$. In combustion synthesis, however, both the temperature and $\mathrm{N}_{2}$ pressure can be variable because of the drastic reaction and abrupt heating or cooling rate. This variance in reaction conditions will change the growth kinetics of TiN crystals and result in a diversity of crystal shapes, such as truncated cubic and pyramidal crystals, as shown in Figure 6 (b) and (c).

From the energy viewpoint, the most stable shape of a crystal is the one with the minimum total surface energy, and this shape is ECS as mentioned before. Driven by the reduction of total surface energy, TiN crystals with other shapes have a tendency to transform into the ECS. That is to say, the quasi-spherical TiN grains will undergo a faceting process to become cubic crystals. If this faceting process is not complete, intermediate products including truncated cubic and pyramidal crystals will be obtained (Figure 6). At the surface of some TiN grains, a terraced structure consisting of a series of layered circular plates is observed, as shown in Figure 7. It is proposed that this terraced structure is caused by the faceting process via two-dimensional nucleation. When a layer grows larger than a critical size, new nuclei can form on it. By this means, the outward growth in the normal direction takes place together with the lateral growth of each layer, and finally produces a series of terraces. 


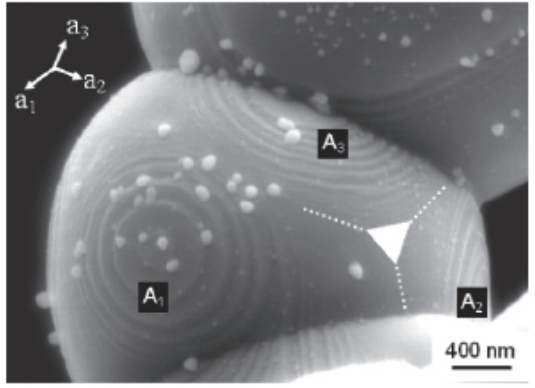

(a)

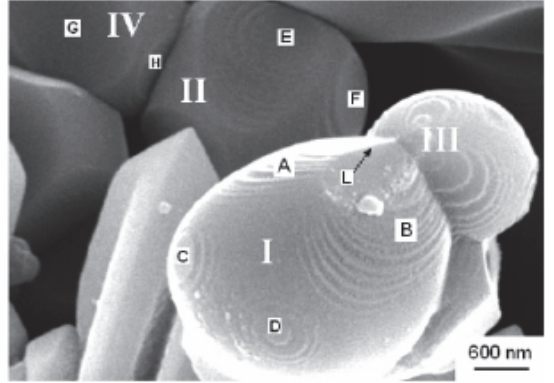

(b)

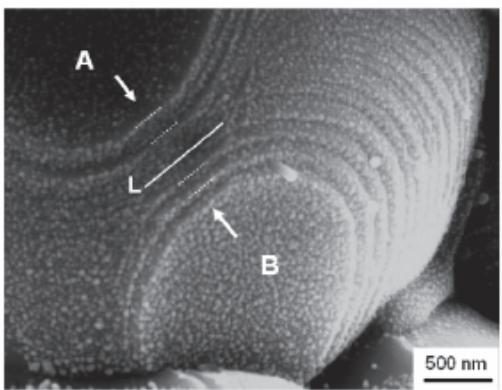

(c)

Fig. 7. SEM images showing a terraced structure on the TiN grains

Figure 8 schematically illustrates the transformation of a spherical TiN grain into a faceted cubic crystal by the faceting process. At first, small facets appear on the surface of the spherical grain. Then, the facets grow in both lateral and normal directions by twodimensional nucleation, and a series of terraces are created. With further growth, two neighboring facets toward different directions will cross and thus an edge forms. At last, nucleation stops and the existing layers expand by lateral growth until they joined at edges. Consequently, a faceted cubic crystal is obtained. The above illustration is supported by SEM observations. For example, Figure 7 (a) shows three series of terraces $\left(A_{1}, A_{2}\right.$, and $\left.A_{3}\right)$ in orthogonal directions, which can develop into three faces of a cubic crystal. Figure 7 (b) shows a faceting grain (II) with a clear tendency to transform into a cubic crystal. Details of the formation edges are shown in Figure 7 (b) and (c).

In the faceting process, the final crystal shape is closely connected with the growth rates of different faces. Variations in growth kinetics can cause different crystal morphologies from the ECS. For example, in the truncated cube shown in Figure 6 (b), \{220\} faces have degraded to edges but $\{222\}$ faces still remained as small triangular facets $\left(A_{1}\right)$. This is probably attributed to the retarded growth at $\{222\}$ faces. As illustrated in Figure 8 (d), only when the ratio of the growth rate of $\{222\}$ faces $\left(V_{T}\right)$ to that of $\{200\}$ faces $\left(V_{A}=V_{B}=V\right)$ is equal or larger than $\sqrt{3},\{222\}$ faces will completely degrade to corners. Otherwise, when $\mathrm{V}_{\mathrm{T}} / \mathrm{V}<\sqrt{3},\{222\}$ faces will be partially reserved and a truncated cube is obtained. If $\mathrm{V}_{\mathrm{T}}$ further decreases to be much smaller than $V,\{222\}$ faces become the most important and the final crystal shape will be an octahedron. The four-fold symmetric pyramidal TiN crystal shown in Figure 6 (c) can be regarded as a half octahedron. 


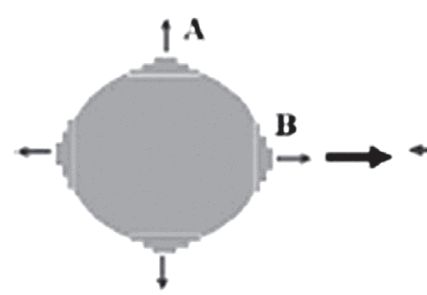

(a)

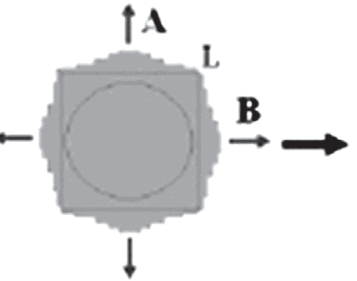

(b)

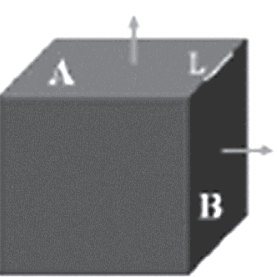

(c)

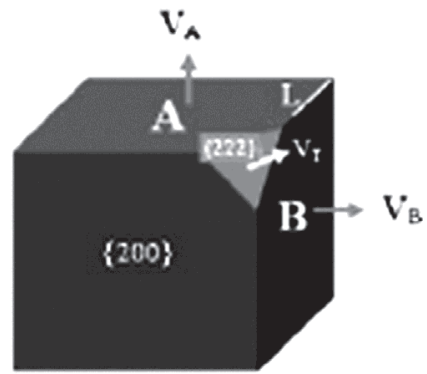

(d)

Fig. 8. A schematic illustration of the faceting process of spherical TiN grains

\subsection{TiN dendrites}

Besides quasi-spherical grains and faceted crystals, TiN dendrites are also observed in the product. Dendrites are usually found in metal ingots from fast cooling of melts, and the formation of TiN dendrites here should be attributed to the fast cooling rate in combustion synthesis. The TiN dendrites exhibit interesting morphologies like bamboos, trees, and flowers, as shown in Figure 9. The bamboo-like dendrite has a wavy shape with sharp tips at its side faces, and with the growth of the tips a teeth-like morphology can be formed. Figure 9 (e) shows some small dendrites with round tips in four directions, which will grow into branches of tree-like dendrites. When several neighboring dendrites grow simultaneously toward different directions, larger flower-like dendrites will be produced. Despite the difference in apparent morphologies, all the TiN dendrites show a four-fold symmetry. In the formation of a dendrite, secondary branches grow perpendicular to a primary truck and smaller twigs perpendicular to a branch. By this means, the TiN dendrites grow in three orthogonal directions. In one direction, several growth units are connected or overlapped, and in the plane normal to this direction each growth unit grows in the other two perpendicular directions.

Based on SEM observation, the growth mechanism of the TiN dendrites is proposed as follows. As shown in Figure 10, in each dendrite, the three orthogonal growth directions are parallel to the reference axes of $a, b$, and $c$, respectively, and the four-fold symmetric pyramids are bounded with $\{222\}$ faces. Figure 10 (c) illustrates a unit growing in the plane normal to $c$-axis. In the directions of $a$ and $b$, four horns grow simultaneously, where the final morphology depends on the growth rates in forward $\left(V_{N}\right)$ and lateral $\left(V_{R}\right)$ directions. If $\mathrm{V}_{\mathrm{R}}=\mathrm{V}_{\mathrm{N}}$, the horns will reserve their initial shape during growth. If $\mathrm{V}_{\mathrm{R}}>>\mathrm{V}_{N}$, the horns will grow quickly in forward directions and the lateral growth is limited, thus developing into slim branches finally. 


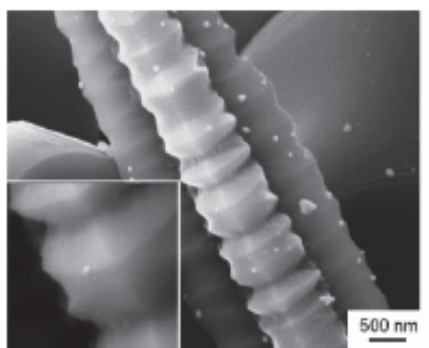

(a)

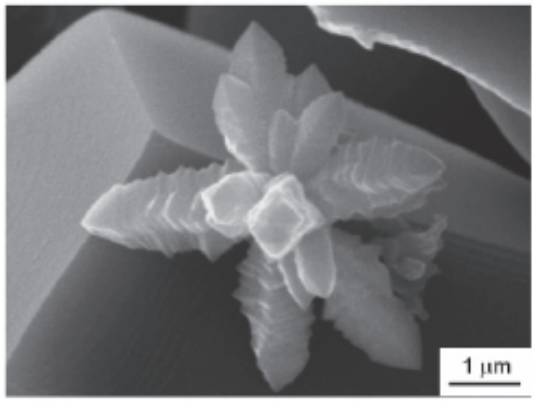

(d)

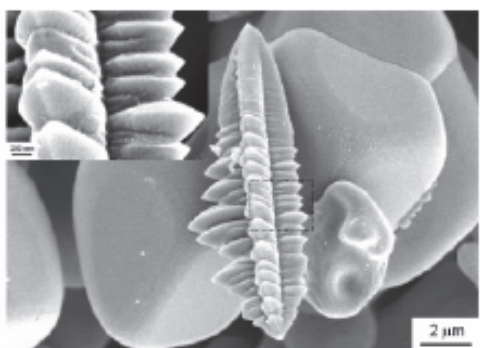

(b)

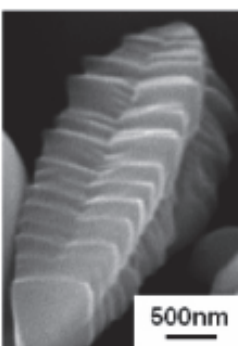

(c)

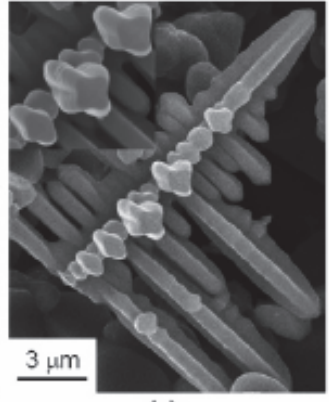

(e)

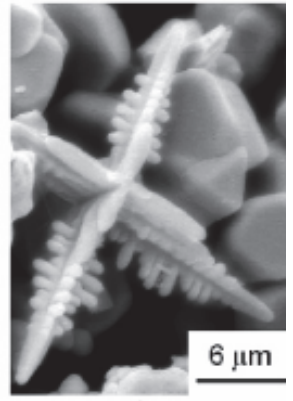

(f)

Fig. 9. SEM images of TiN dendrites

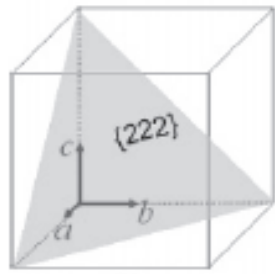

(a)

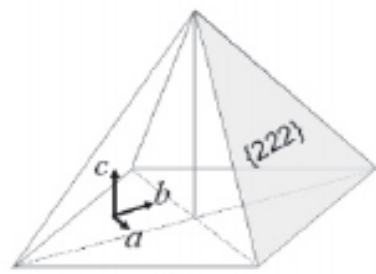

(b)

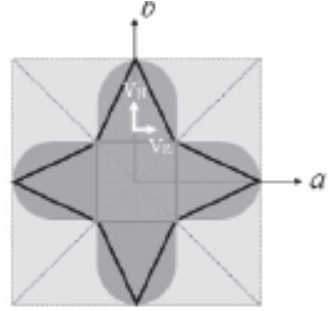

(c)

Fig. 10. An illustration of the growth mechanism of TiN dendrites

\section{Combustion synthesis of nano-sized SiC powders}

$\mathrm{SiC}$ ceramics are widely studied for tribological and structural applications, such as abrasives, refractories, bearings, valves, and seals, because of its high elastic modulus and hardness, excellent oxidation and corrosion durability, high strength at elevated temperatures, and good thermal shock resistance. Consolidated SiC ceramics are usually prepared by sintering techniques including liquid-phase sintering, hot-pressing, and spark plasma sintering [9-12]. In these sintering processes, both densification kinetics and microstructure evolution strongly depend on the quality of starting powders. At the same time, the fabrication cost of sintered $\mathrm{SiC}$ ceramic components is also largely determined by that of the starting $\mathrm{SiC}$ powders. 
The most conventional approach to prepare $\mathrm{SiC}$ powders is the Acheson method, which is based on the carbothermal reduction of silica at high temperatures above $2000^{\circ} \mathrm{C}$. $\mathrm{SiC}$ powders produced by this method have large particle size and hence post-treatment by extensive milling is required to improve the sinterability. Such milling process, however, is inevitably accompanied by the contamination of milling media. By pyrolysis or reaction of silane compounds, high-purity and ultrafine $\mathrm{SiC}$ powders can be synthesized. A major drawback of this method is the high cost, which limits its application for large-scale industrial production.

From the viewpoint of reducing costs, combustion synthesis is a desirable technique to produce $\mathrm{SiC}$ powders. Because $(\mathrm{Si}+\mathrm{C})$ system is weakly exothermic, combustion synthesis of $\mathrm{SiC}$ requires extra energy input by mechanical activation, preheating, microwave radiation, or electric field activation. Combustion synthesis of $\mathrm{SiC}$ can also be carried out in a highpressure $\mathrm{N}_{2}$ atmosphere, where nano-sized powders can be obtained [13].

Figure 11 shows the photographs of $\mathrm{SiC}$ product prepared by combustion synthesis in $\mathrm{N}_{2}$.

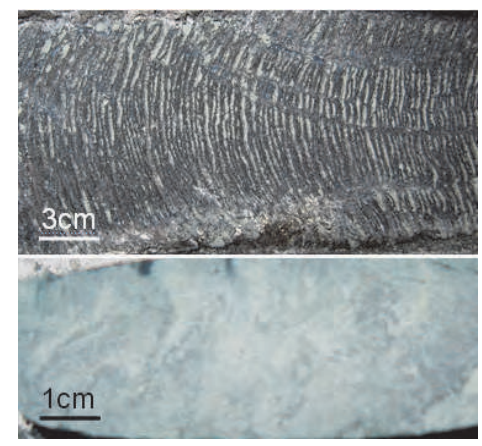

Fig. 11. Photographs of $\mathrm{SiC}$ product prepared by combustion synthesis

The product has a color from grey to light green and can be easily pulverized into powder. On the surface of the product, clear veins are found as a result of propagation of combustion wave. XRD analysis (Figure 12) confirms that the product is almost single-phase $\beta$-SiC. SEM observation (Figure 13) reveals that the as-synthesized SiC powder is very fine and the average grain size is below $100 \mathrm{~nm}$.

As a weakly exothermic system, the self-sustained reaction of $\mathrm{Si}+\mathrm{C}=\mathrm{SiC}$ is difficult to realize in vacuum or an $\mathrm{Ar}$ atmosphere. In this case, in the preparation of $\mathrm{SiC}$ powders by combustion synthesis, $\mathrm{N}_{2}$ plays an important role. Nevertheless, no $\mathrm{Si}_{3} \mathrm{~N}_{4}$ has been found in the products. Moreover, there is no significant decrease in the pressure of $\mathrm{N}_{2}$ after combustion reaction, which implies that the $\mathrm{N}_{2}$ has not been consumed. Then, what ever role does $\mathrm{N}_{2}$ play in the combustion synthesis of $\mathrm{SiC}$ and how does it affect the reaction? To solve this problem, an incomplete product gives some instructive information. In the incomplete product, there are several dark areas that have not fully reacted. XRD analysis (Figure 14) reveals that in the partially-reacted areas much $\mathrm{Si}_{3} \mathrm{~N}_{4}$ is present other than the major $\mathrm{SiC}$ phase, which is further confirmed by TEM observation shown in Figure 15. From these results, a two-step reaction mechanism is proposed for the combustion synthesis of $\mathrm{SiC}$ in $\mathrm{N}_{2}$. In the first step, $\mathrm{Si}$ reacts with $\mathrm{N}_{2}$ to form $\mathrm{Si}_{3} \mathrm{~N}_{4}$, which decomposes in the second step and the released $\mathrm{Si}$ reacts with $\mathrm{C}$ to produce $\mathrm{SiC}$. Here, $\mathrm{N}_{2}$ acts as a catalyst in fact, which is consumed first and released later. In this way, the pressure of $\mathrm{N}_{2}$ will not decrease after the reaction. 


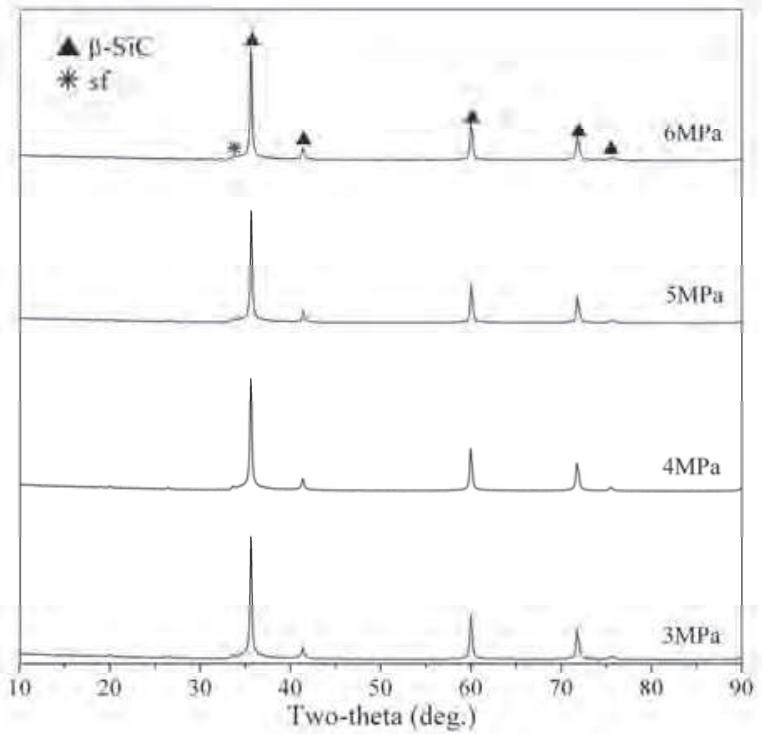

Fig. 12. XRD patterns of $\mathrm{SiC}$ powders prepared by combustion synthesis under different $\mathrm{N}_{2}$ pressures
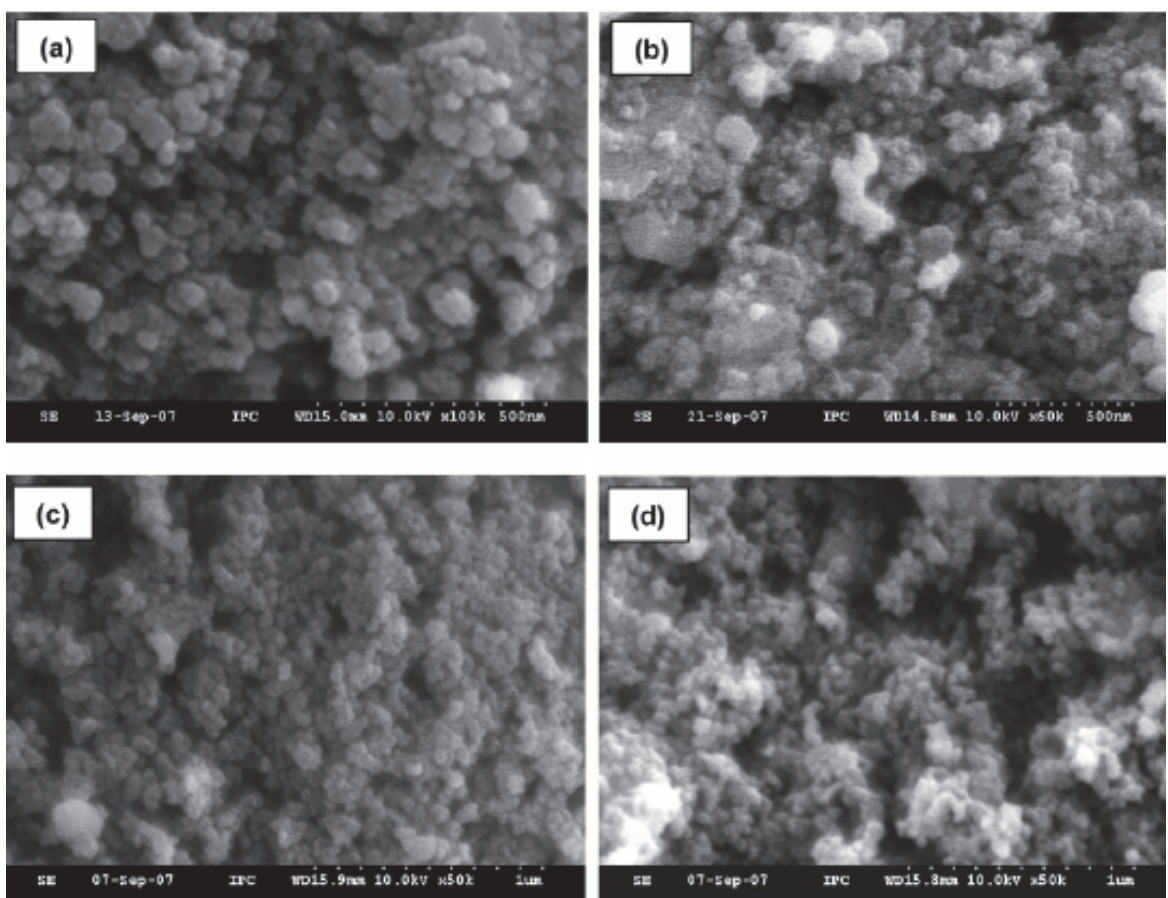

Fig. 13. SEM images of $\mathrm{SiC}$ powders prepared by combustion synthesis in high-pressure $\mathrm{N}_{2}$ 

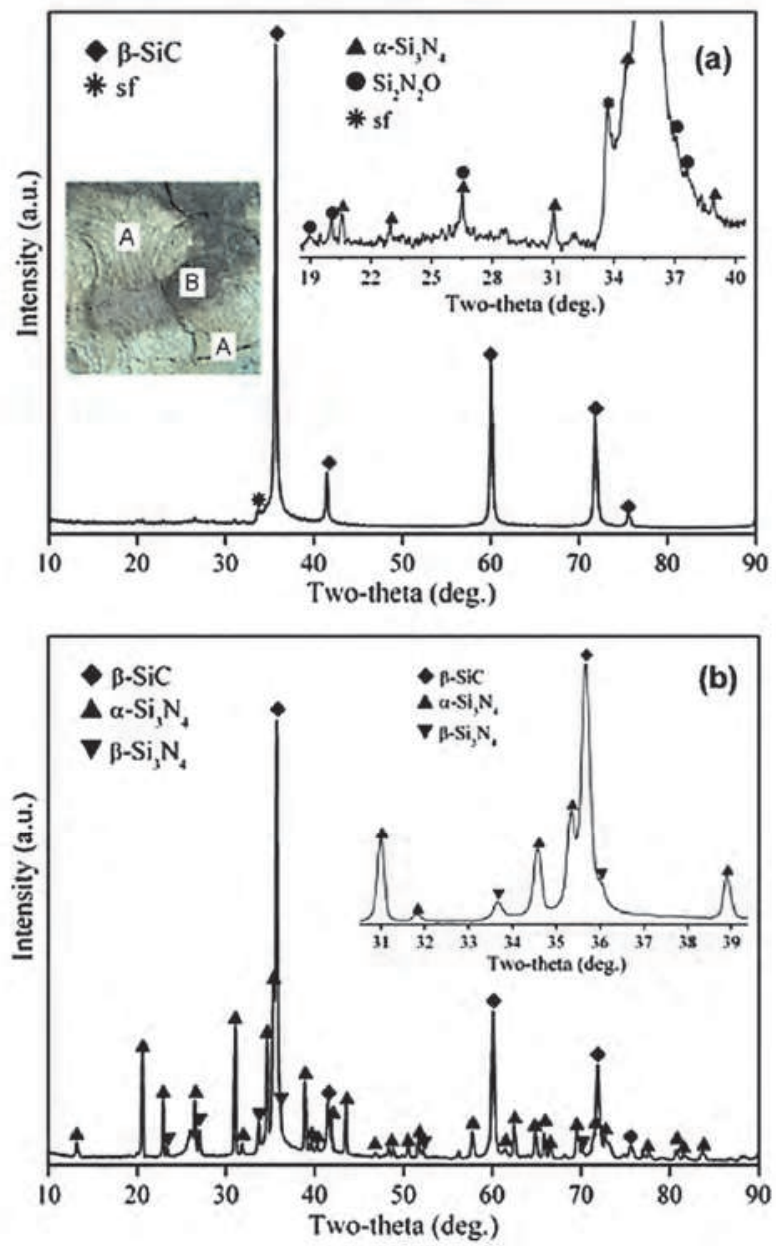

Fig. 14. XRD patterns of (a) fully-reacted and (b) partially-reacted products in combustion synthesis of $\mathrm{SiC}$ in high-pressure $\mathrm{N}_{2}$

For further understanding the chemical reactions in the Si-N-C system, thermodynamical calculation is carried out based on the reaction

$$
\mathrm{Si}_{3} \mathrm{~N}_{4}(\mathrm{~s})+3 \mathrm{C}(\mathrm{s})=3 \mathrm{SiC}(\mathrm{s})+2 \mathrm{~N}_{2}(\mathrm{~g})
$$

According to reported thermodynamic data, the Gibbs free energy change $(\Delta G)$ of Reaction (1) can be worked out as

$$
\Delta \mathrm{G}=591450-314.8 \mathrm{~T}+\mathrm{RT} \ln \mathrm{K}_{\mathrm{R}}
$$

where $K_{R}$ is the reaction equilibrium constant. Assuming that the activity coefficients of solid reactants equal to 1 , the equilibrium constant can be further written as 


$$
\mathrm{K}_{\mathrm{R}}=\mathrm{P}^{2}\left(\mathrm{~N}_{2}\right)
$$

In Equations (2) and (3), the units of $\Delta \mathrm{G}$ and $\mathrm{T}$ are $\mathrm{J} \cdot \mathrm{mol}^{-1}$ and $\mathrm{K}$, the unit of $\mathrm{P}\left(\mathrm{N}_{2}\right)$ is $\mathrm{P}^{\mathrm{e}}$ $\left(\mathrm{P}^{\mathrm{\theta}}=10^{5} \mathrm{~Pa}\right)$, the equilibrium constant of $K_{\mathrm{R}}$ is dimensionless, and $\mathrm{R}$ is gas constant equal to $8.31 \mathrm{~J} \cdot \mathrm{mol}^{-1} \cdot \mathrm{K}^{-1}$.

At equilibrium state

$$
\Delta \mathrm{G}(\mathrm{P}, \mathrm{T})=0
$$

Thus the pressure of $\mathrm{N}_{2}$ can be expressed as the function of temperature

$$
\log P\left(\mathrm{~N}_{2}\right)=7.23-15459 /(\mathrm{T}+273)
$$

where the units of $\mathrm{P}\left(\mathrm{N}_{2}\right)$ and $\mathrm{T}$ are converted to $\mathrm{MPa}$ and ${ }^{\circ} \mathrm{C}$, for the convenience of discussion.
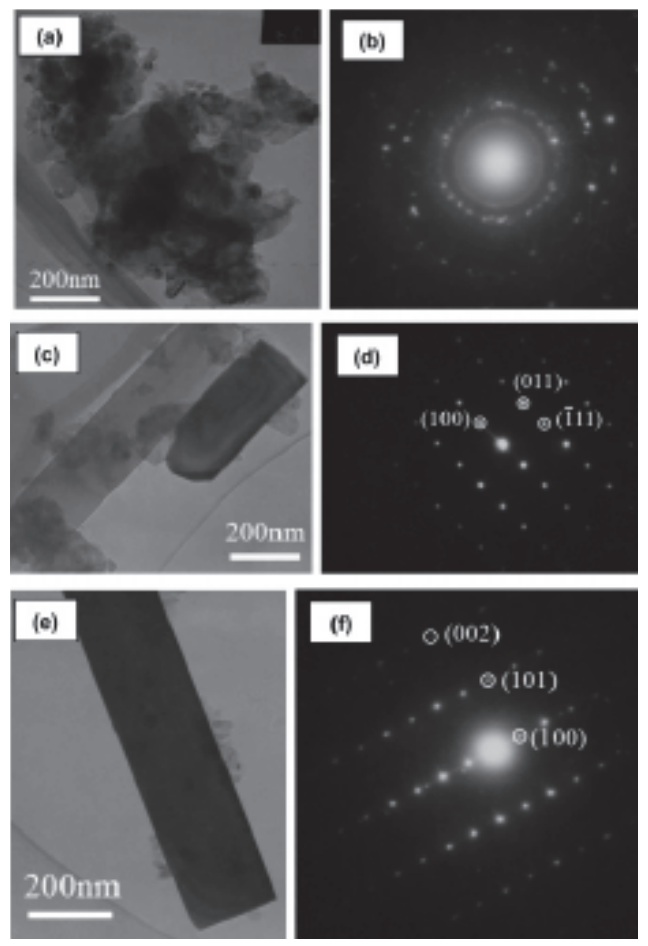

Fig. 15. TEM images and SAED patterns of the phases obtained in the partially-reacted product: (a) and (b) $\beta-S i C$; (c) and (d) $\alpha-\mathrm{Si}_{3} \mathrm{~N}_{4}$; (e) and (f) $\beta-\mathrm{Si}_{3} \mathrm{~N}_{4}$

According to Equation (5), the relationship between $\mathrm{P}\left(\mathrm{N}_{2}\right)$ and $\mathrm{T}$ is plotted in Figure 16. By the $\mathrm{P}\left(\mathrm{N}_{2}\right)$-T curve, the reference frame is divided into two parts with different phases being stable. The formation of $\mathrm{SiC}$ is favored at higher temperature and lower $\mathrm{N}_{2}$ pressure. For a certain pressure of $\mathrm{N}_{2}$, there is an equilibrium temperature beyond which $\mathrm{Si}_{3} \mathrm{~N}_{4}$ will decompose and $\mathrm{SiC}$ will be formed. With increasing pressure of $\mathrm{N}_{2}$, the decomposition temperature of $\mathrm{Si}_{3} \mathrm{~N}_{4}$ increases. 


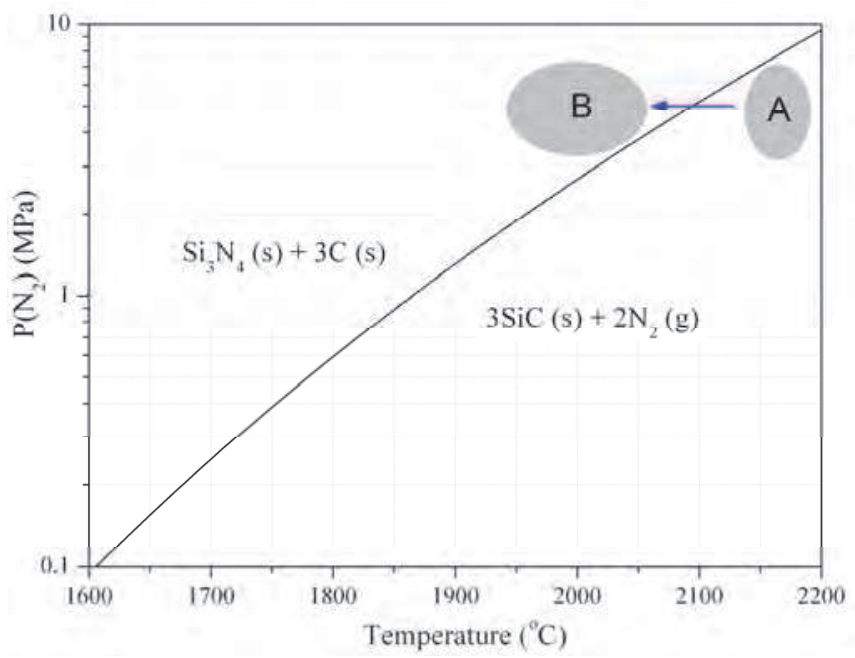

Fig. 16. Thermodynamical evaluation on the stability of possible phases in Si-C-N system

Finally, about the formation of $\mathrm{SiC}$ by the reaction between $\mathrm{Si}$ and $\mathrm{C}$, several mechanisms have been reported [14-16], with either interface reaction or diffusion being the rate-limiting process. For combustion synthesis of $\mathrm{SiC}$ in $\mathrm{N}_{2}$, most starting $\mathrm{Si}$ particles react with $\mathrm{N}_{2}$ to form $\mathrm{Si}_{3} \mathrm{~N}_{4}$. The $\mathrm{Si}$ species directly responsible for the formation of $\mathrm{SiC}$ come from the decomposition of $\mathrm{Si}_{3} \mathrm{~N}_{4}$ and can be regarded as regenerate $\mathrm{Si}$. Because the decomposition temperature of $\mathrm{Si}_{3} \mathrm{~N}_{4}$ is much higher than the melting point of $\mathrm{Si}$, the regenerate $\mathrm{Si}$ will exist in a melt or vapor state. Carbon particles are coated by $\mathrm{Si}$ melt, and $\mathrm{SiC}$ forms first at the solid-liquid interface. The continued reaction is controlled by the diffusion of $C$ through the $\mathrm{SiC}$ layer. In addition, $\mathrm{SiC}$ can be produced by the reaction between $\mathrm{C}$ particles with $\mathrm{Si}$ vapor, which is also initiated by interface reaction and then limited by diffusion.

\section{Combustion synthesis of SiAION powders with rod-like crystals}

As a solid-solution of $\mathrm{Si}_{3} \mathrm{~N}_{4}$, $\mathrm{SiAlON}$ ceramics exhibit good mechanical properties such as high hardness, superior wear durability, and excellent thermal shock resistance, making them promising for tribological and high-temperature applications $[17,18]$. The properties of SiAlON ceramics strongly depend on their chemical compositions and microstructure including grain morphology and size. For example, the fracture toughness of SiAlON ceramics can be greatly improved by developing coarse elongated grains $[19,20]$. In this aspect, seeding has been proved to be an effective method to induce isotropic growth of SiAlON and formation of elongated grains. The seeds used in this method are usually rodlike SiAlON crystals. For prepare such crystals, combustion synthesis is an effective technique, and by this technique two kinds of rod-like SiAlON crystals have been prepared [21-25], which are known as a-SiAlON and $\beta-S i A l O N$, respectively.

\subsection{Rod-like $\alpha$-SiAION crystals}

According to the general chemical formula of $\mathrm{R}_{\mathrm{m} / \mathrm{z}} \mathrm{Si}_{12-(\mathrm{m}+\mathrm{n})} \mathrm{Al}_{\mathrm{m}+\mathrm{n}} \mathrm{O}_{\mathrm{n}} \mathrm{N}_{16-\mathrm{n}}$ ( $\mathrm{R}$ means the stabilizing cations), from the raw materials of $\mathrm{CaCO}_{3}, \mathrm{Yb}_{2} \mathrm{O}_{3}, \mathrm{Si}, \mathrm{Al}, \mathrm{a}-\mathrm{Si}_{3} \mathrm{~N}_{4}, \mathrm{AlN}, \mathrm{SiO}_{2}$, and 
$\mathrm{NH}_{4} \mathrm{~F}$, Ca and $\mathrm{Yb}$-stabilized $\mathrm{a}-\mathrm{SiAlON}$ can be prepared by combustion synthesis, with chemical compositions of $\mathrm{Ca}_{0.8} \mathrm{Si}_{8.8} \mathrm{Al}_{3.2} \mathrm{O}_{1.6} \mathrm{~N}_{14.4}(\mathrm{~m}=\mathrm{n}=1.6)$ and $\mathrm{Yb}_{0.5} \mathrm{Si}_{9.5} \mathrm{Al}_{2.5} \mathrm{O}_{1.0} \mathrm{~N}_{15.0}(\mathrm{~m}=1.5$, $\mathrm{n}=1.0$ ), respectively. For Ca-stabilized system the product is a-SiAlON with minor AlN and $\mathrm{Si}$, and for $\mathrm{Yb}$-stabilized system almost single-phase a-SiAlON is obtained, as shown in Figure 17.
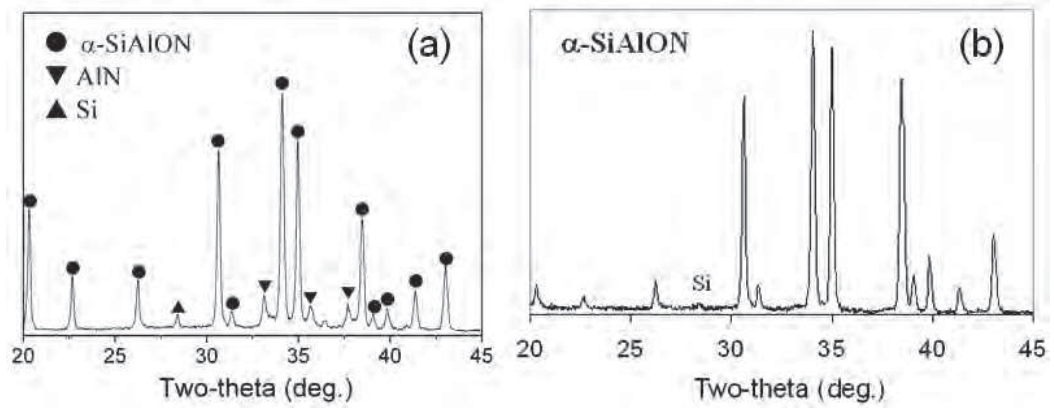

Fig. 17. XRD patterns of a-SiAlON powders prepared by combustion synthesis:

(a) Ca a-SiAlON; (b) Yb a-SiAlON

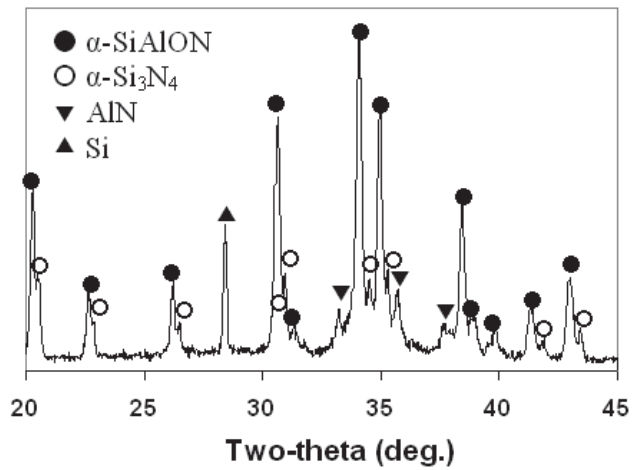

Fig. 18. XRD pattern of the intermediate product during combustion synthesis of Ca a-SiAlON

Since combustion synthesis takes place very quickly, it is difficult to exactly clarify the reaction procedure in detail. In this aspect, the analysis of intermediate product can give some useful information. In combustion synthesis, the reaction at surface layer of samples is usually incomplete because of severe heat loss and as a result some intermediate product is obtained. Figure 18 shows the XRD pattern of the intermediate product in combustion synthesis of $\mathrm{Ca}$ a-SiAlON. In the intermediate product, except for a-SiAlON, a- $\mathrm{Si}_{3} \mathrm{~N}_{4}, \mathrm{AlN}$, and much residual $\mathrm{Si}$ is present. From this result, the reaction procedure during combustion synthesis of Ca a-SiAlON is proposed as follows.

$$
\begin{gathered}
2 \mathrm{Al}+\mathrm{N}_{2}=2 \mathrm{AlN} \\
3 \mathrm{Si}+2 \mathrm{~N}_{2}=\mathrm{a}-\mathrm{Si}_{3} \mathrm{~N}_{4} \\
\mathrm{CaCO}_{3}=\mathrm{CaO}+\mathrm{CO}_{2}
\end{gathered}
$$




$$
\begin{gathered}
\mathrm{CaO}+\mathrm{SiO}_{2}+\mathrm{Al}_{2} \mathrm{O}_{3} \rightarrow \mathrm{Ca}-\mathrm{Si}-\mathrm{Al}-\mathrm{O} \text { liquid phase } \\
\text { Ca-Si-Al-O liquid phase }+\mathrm{a}_{-} \mathrm{Si}_{3} \mathrm{~N}_{4}+\mathrm{AlN} \rightarrow \mathrm{Ca}-\mathrm{Si}-\mathrm{Al}-\mathrm{O}-\mathrm{N} \text { liquid phase } \\
\text { Ca-Si-Al-O-N liquid phase } \rightarrow \text { Ca a-SiAlON }
\end{gathered}
$$

It should be pointed out that, this proposition just outlines possible major reactions and the actual combustion reaction is more complicated. The above reactions can take place simultaneously and overlap with each other.

Figure 19 shows the SEM images of as-synthesized a-SiAlON powders, which consist of rod-like crystals. From the low-magnification image, a flower-like morphology is observed, which is caused by simultaneous growth of many rod-like crystals. The formation of the rod-like a-SiAlON crystals is thought to be related with the special reaction condition in combustion synthesis characterized by high temperature and fast heating rate. Under this reaction, a non-equilibrium reaction state will be caused, where the chemical composition of the co-existing liquid phase remarkably deflects from that in equilibrium with the a-SiAlON crystals. In this case, a strong driving force for mass transportation and crystal growth will be created. Hence, the a-SiAlON crystals undergo a rapid anisotropic growth by a dynamic ripening mechanism and develop into a rod-like morphology.
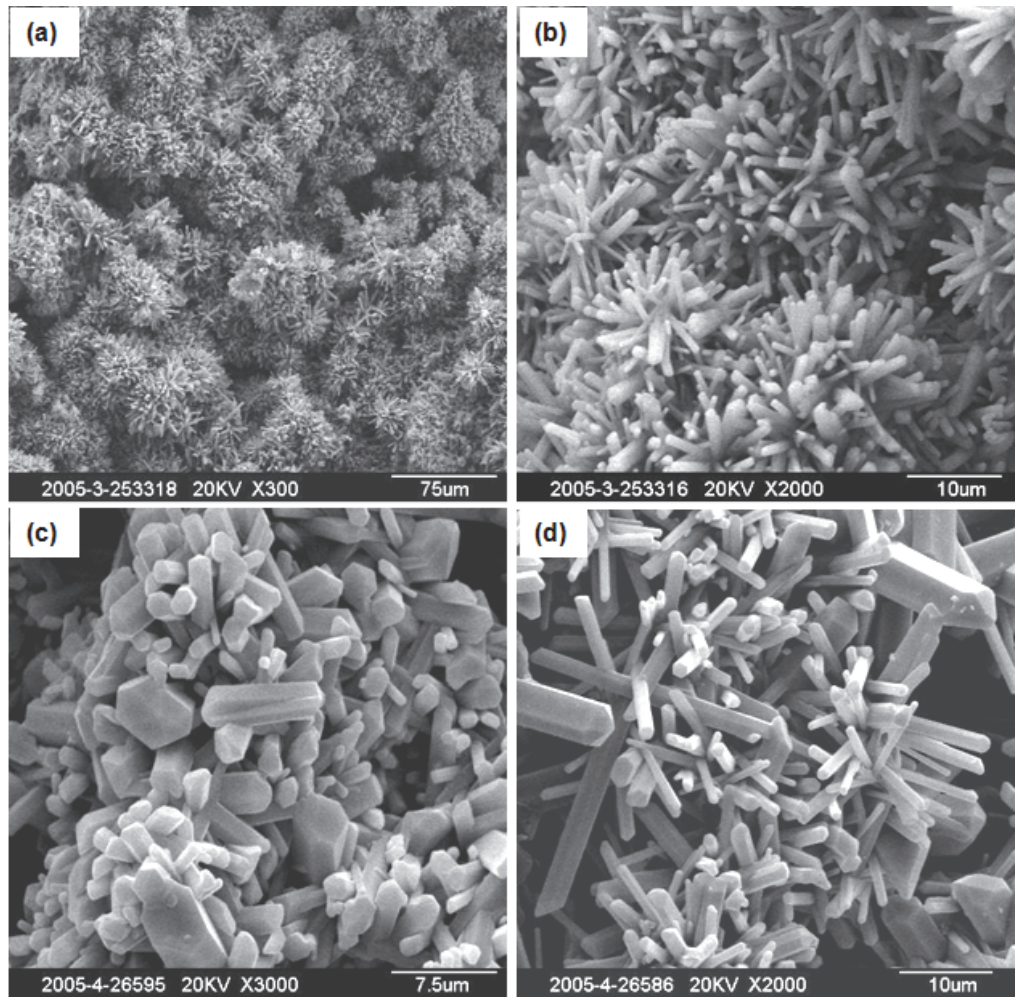

Fig. 19. SEM images of a-SiAlON powders prepared by combustion synthesis: (a) and (b) Ca a-SiAlON; (c) and (d) Yb a-SiAlON 
The anisotropic growth of rod-like a-SiAlON crystals in combustion synthesis is further studied by TEM. As shown in Figure 20, the preferred growth direction of rod-like aSiAlON crystals is [001] and parallel to the c-axis in the hexagonal lattice. This is consistent with the prediction from the intrinsic crystallography characteristics of a-SiAlON. In the hexagonal lattice of a-SiAlON with $c / a<1$, the basal face has a lower atom packing density and smaller grid distance compared with the prismatic side faces. Accordingly, the basal face has the priority for nucleation and a higher growth rate, leading to the rod-like morphology of a-SiAlON crystals.
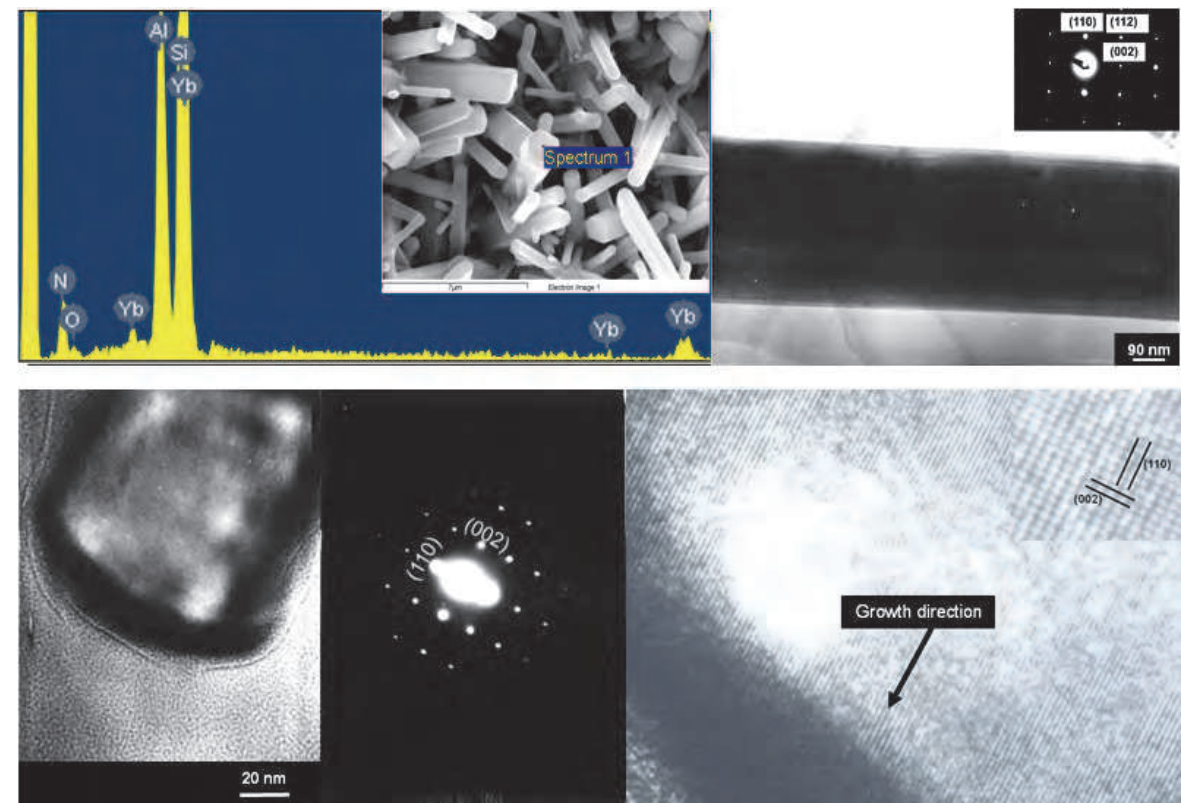

Fig. 20. EDS spectrum and micrographs of rod-like Yb a-SiAlON crystals

Besides the intrinsic lattice structure, reaction conditions also have a strong effect on the growth of a-SiAlON crystals. For example, in most sintered a-SiAlON ceramics, equiaxed grains are more frequently observed than rod-like crystals. This is because that, in the sintering of a-SiAlON, a-Si ${ }_{3} \mathrm{~N}_{4}$ is usually used as raw materials. The $a-\mathrm{Si}_{3} \mathrm{~N}_{4}$ grains can provide preferred nucleation sites and cause the formation of too much a-SiAlON nuclei. In later growth stage, a large amount of a-SiAlON grains impinge on each other and this steric hindrance suppresses the growth of rod-like crystals. On the other hand, the growth of aSiAlON generally occurs by Ostwald ripening, where small grains dissolve into a coexisting liquid and the species are transported by diffusion to larger grains and precipitated there. In this dissolution-diffusion-reprecipitation process, fast anisotropic grain growth is often retarded by slow dissolution or mass transportation.

Compared with conventional sintering, combustion synthesis can create a non-equilibrium reaction state and provide a strong driving force for fast growth of a-SiAlON crystals by a dynamic ripening process. At the same time, combustion reaction progresses rapidly and the high heating rate limits the nucleation. In this way, combustion synthesis can offer the opportunity for the growth of rod-like a-SiAlON crystals. 
In combustion synthesis of a-SiAlON, the growth of rod-like crystals can be affected by introducing proper additives. For example, with the addition of $\mathrm{NH}_{4} \mathrm{~F}$ and $\mathrm{Fe}_{2} \mathrm{O}_{3}$, faceted prismatic rod-like $\mathrm{Yb}$ a-SiAlON crystals have been prepared, as shown in Figure 21. The rod-like crystals show different morphologies at their heads, such as facets, pyramids, and incomplete pyramids as a transition from facets to pyramids. In the formation of rod-like aSiAlON crystals, different nucleation modes can be operative. Nucleation can take place based on the un-dissolved $\mathrm{Si}_{3} \mathrm{~N}_{4}$ grains or on the side and basal faces of present rod-like aSiAlON crystals. When nucleation occurs on the basal face, a terraced morphology will be produced, where new crystals have a hexagonal shape similar to the substrate crystals with the c-axis and side faces being parallel. It appears that the nucleation and growth of new crystals are not random but epitaxial with strict orientation relations to the substrate crystals. When this epitaxial nucleation occurs on an incomplete pyramidal substrate crystal, a T-like morphology is produced, as illustrated in Figure 22.

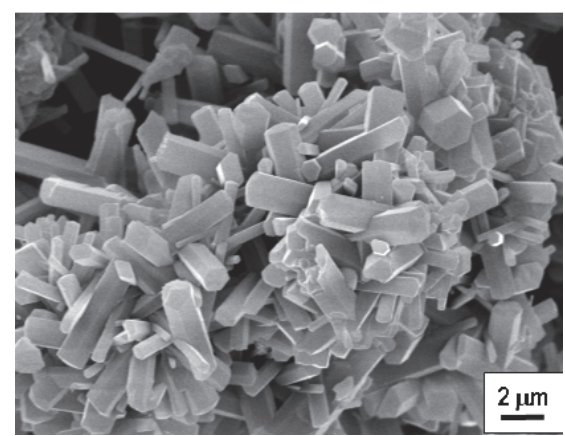

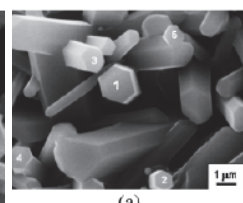

(a)

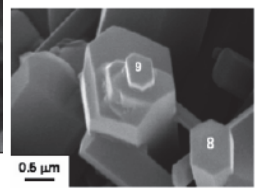

(d)
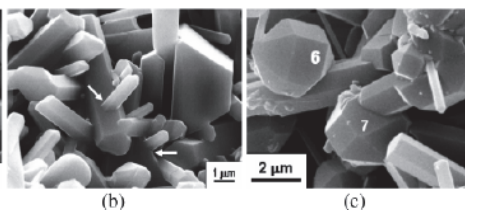

(c)

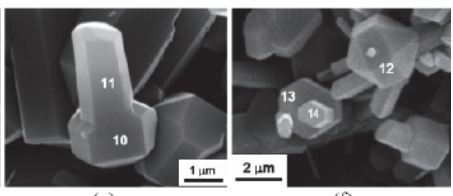

(e)

(f)

Fig. 21. SEM image of rod-like Yb a-SiAlON crystals with different head morphologies
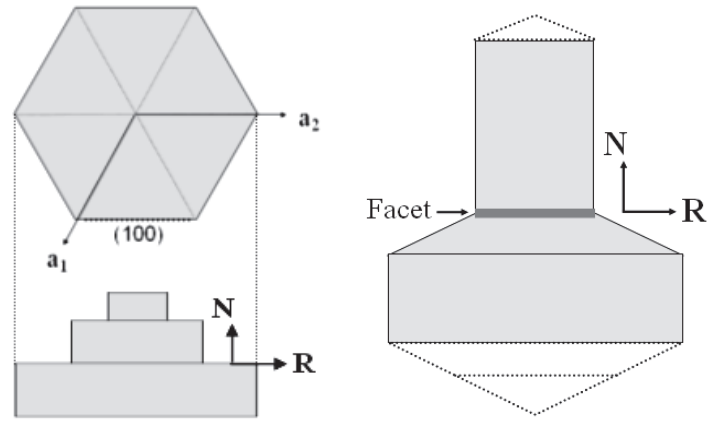

Fig. 22. An illustration of the formation of different head morphologies in rod-like a-SiAlON crystals

\subsection{Rod-like $\beta$-SiAION crystals}

Besides a-SiAlON, $\beta$-SiAlON is another important polymorph in the SiAlON family. $\beta$ SiAlON is the solid solution of $\beta-\mathrm{Si}_{3} \mathrm{~N}_{4}$, where $\mathrm{Si}-\mathrm{N}$ bonds are partially substituted by $\mathrm{Al}-\mathrm{O}$ bonds. The composition of $\beta$-SiAlON can be represented by a general chemical formula of $\mathrm{Si}_{6-\mathrm{z}} \mathrm{Al}_{\mathrm{z}} \mathrm{O}_{\mathrm{z}} \mathrm{N}_{8-\mathrm{z}}(0<\mathrm{z}<4.2)$. From the raw materials of $\mathrm{Si}, \mathrm{Al}, \mathrm{Si}_{3} \mathrm{~N}_{4}, \mathrm{Al}_{2} \mathrm{O}_{3}, \mathrm{SrCO}_{3}$, and $\mathrm{NH}_{4} \mathrm{~F}, \beta-$ 
SiAlON powders can be prepared by combustion synthesis. Figure 23 shows the XRD pattern of $\beta$-SiAlON powders prepared by combustion synthesis. It is clear that single-phase $\beta$-SiAlON is obtained without any impurities. SEM observation (Figure 24 ) reveals that the $\beta$-SiAlON powders consist of prismatic rod-like crystals. By the addition of $\mathrm{SrCO}_{3}$ and $\mathrm{NH}_{4} \mathrm{~F}$, the aspect ratios of the rod-like crystals are increased. It is reported that the anisotropic growth of $\beta$-SiAlON crystals is caused by preferential interfacial segregation $[26,27]$. This segregation is related with the basicity of metallic oxides and more basic oxides result in stronger segregation. Because $\mathrm{SrO}$ is more basic than $\mathrm{SiO}_{2}$ and $\mathrm{Al}_{2} \mathrm{O}_{3}$, the interfacial segregation will be enhanced by adding $\mathrm{SrCO}_{3}$, which improves the anisotropic growth of rod-like $\beta$-SiAlON crystals.

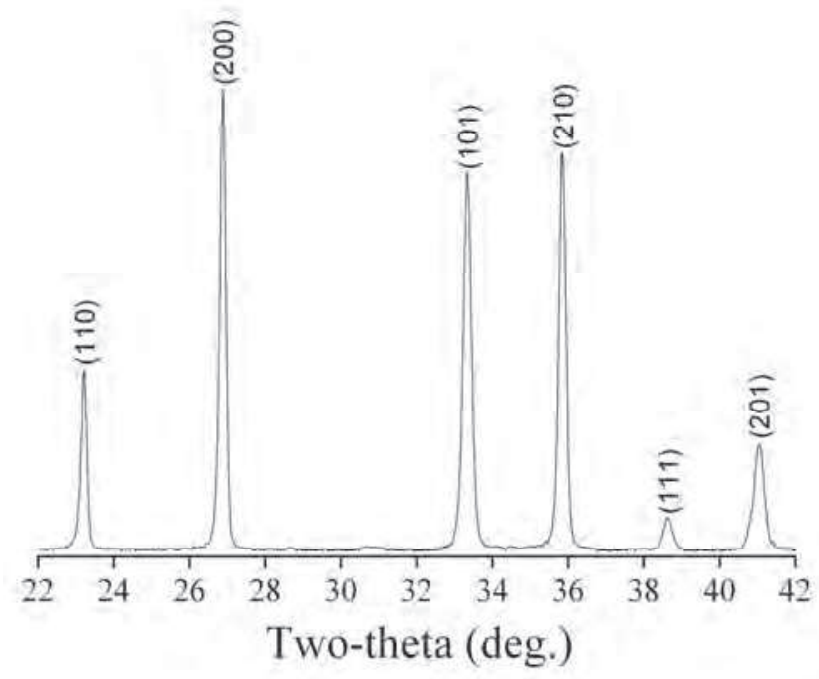

Fig. 23. XRD pattern of $\beta$-SiAlON powders prepared by combustion synthesis

In addition to rod-like crystals, micropalings with nanorods are observed in $\beta$-SiAlON powders prepared by combustion synthesis, as shown in Figure 25. The nanorods are produced on side faces of the coarse prismatic crystals, and the thickness of most nanorods is in the range of 50-150 $\mathrm{nm}$. In each micropaling, nanorods are aligned around a large prismatic crystal in the direction parallel to the side faces. TEM characterizations (Figure 26) reveal that the preferred growth direction of the nanorods is [001].

The anisotropic growth of $\beta-\mathrm{Si}_{3} \mathrm{~N}_{4}$ and $\beta-\mathrm{SiAlON}$ crystals has been widely studied and generally attributed to different structures and growth kinetics at the basal and side faces [28-30]. Some studies suggest that, the basal face is atomically rough while the side faces are smooth, and thus the crystal growth rate is controlled by diffusion at the basal face and by interfacial reaction at the side faces. In this case, the basal face has a higher growth rate than the side faces, leading to the anisotropic growth and formation of rod-like crystals. According to the periodic bond chain (PBC) theory, the ideal crystallization shape of $\beta-\mathrm{Si}_{3} \mathrm{~N}_{4}$ has been theoretically predicted to be an elongated prism bounded by $\{100\}$ and $\{101\}$ faces [31]. When a large amount of oxygen is present, the $\{101\}$ faces can be replaced by $\{001\}$ ones. 

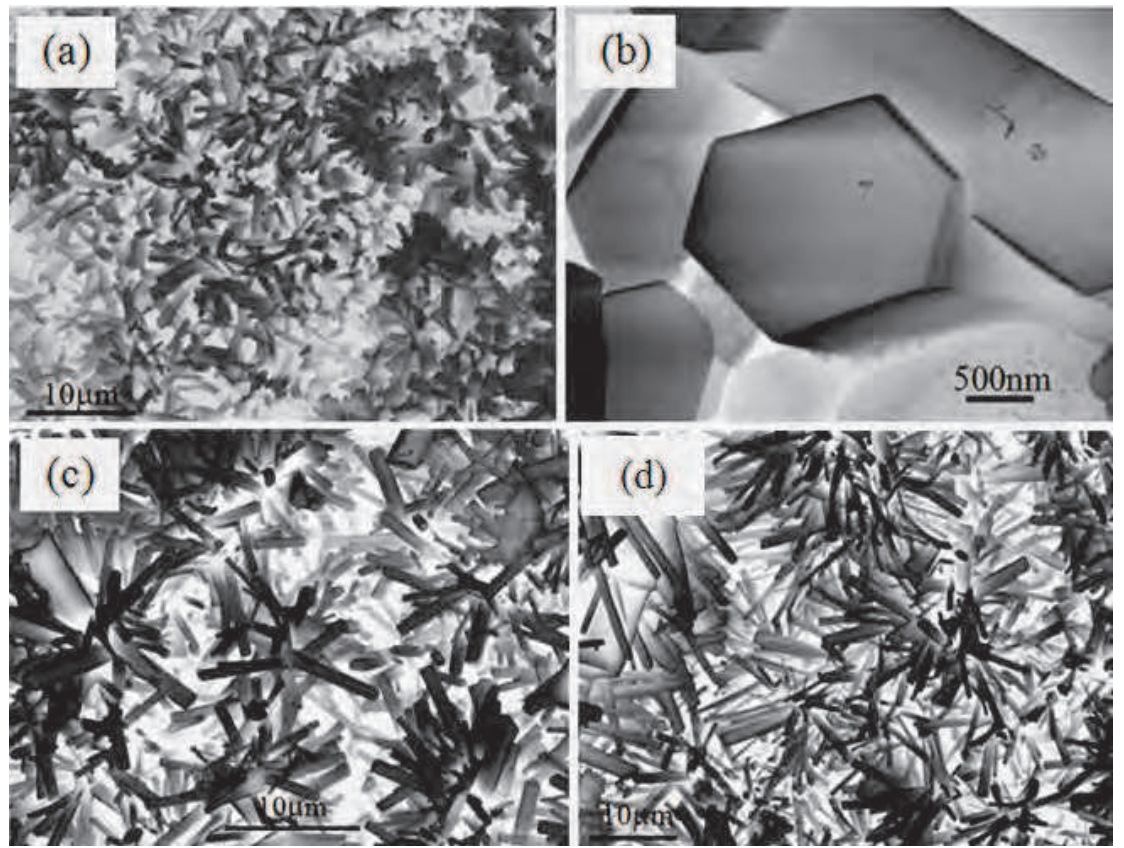

Fig. 24. SEM images of $\beta$-SiAlON powders prepared by combustion synthesis: (a) and (b) with no additives; (c) with 4 wt. $\% \mathrm{SrCO}_{3}$; (d) with 2 wt. $\% \mathrm{SrCO}_{3}$ and 2 wt. $\% \mathrm{NH}_{4} \mathrm{~F}$
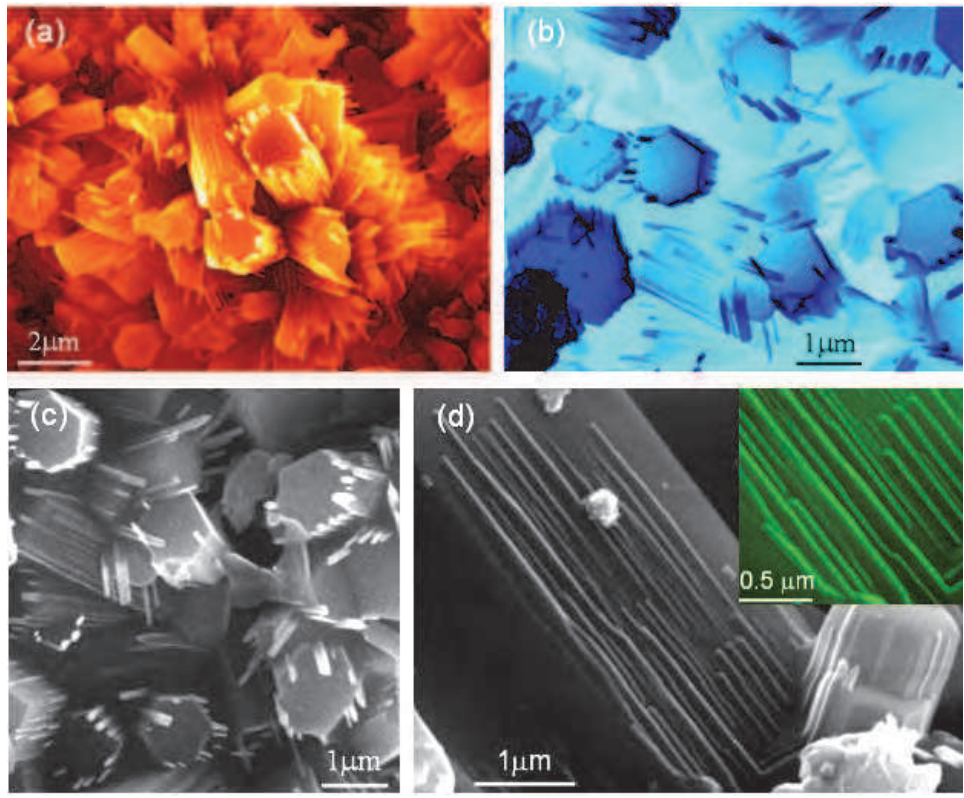

Fig. 25. SEM images of $\beta$-SiAlON micropalings with nanorods 

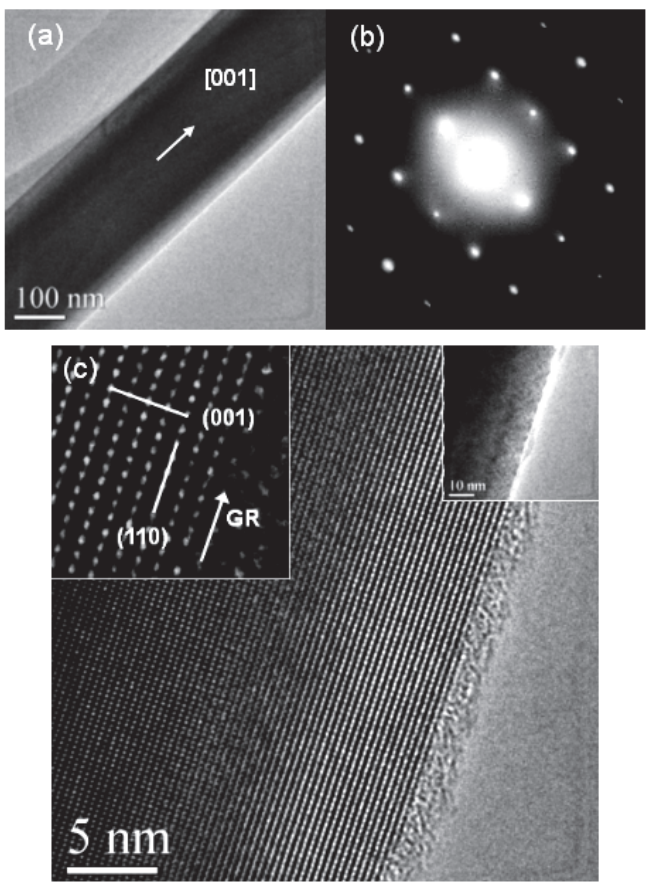

Fig. 26. TEM photographs of $\beta$-SiAlON nanorods with SAED pattern

From the above experimental results and discussion, an epitaxial nucleation and anisotropic growth mechanism is proposed to explain the formation of $\beta$-SiAlON micropalings. This mechanism includes two primary hypotheses: (1) epitaxial nucleation on side faces of coarse prismatic crystals; (2) anisotropic growth of nanorods in [001] direction. By epitaxial nucleation, a new crystal forms on a side face of a coarse prismatic crystal and then grows in three orthogonal directions, as illustrated in Figure 27. If the growth rate in the preferred direction $\left(\mathrm{V}_{\mathrm{C}}\right)$ is much higher than those in two lateral directions $\left(\mathrm{V}_{\mathrm{A}}\right.$ and $\left.\mathrm{V}_{\mathrm{B}}\right)$, the new crystal undergoes an anisotropic growth and develop into a slim nanorod. With the formation of more nanorods around the central coarse crystal, a micropaling is produced.
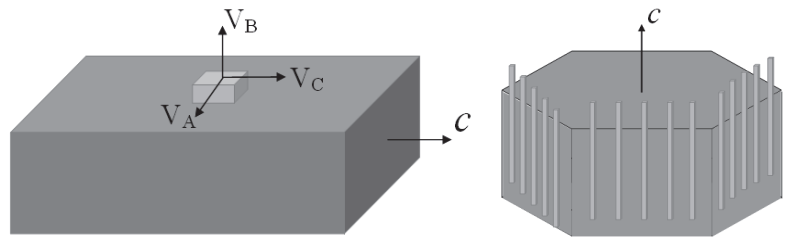

Fig. 27. A schematic illustration of the formation of $\beta$-SiAlON micropalings

\section{Combustion synthesis of Ti-AI-C powders with lamellar grains}

The lamellar ceramics in the Ti-Al-C ternary system have unique physical and mechanical properties, such as high melting point, good thermal and electrical conductivity, and 
machinability by both electrical discharge method and conventional cutting tools [32-34]. Among these ceramics, $\mathrm{Ti}_{3} \mathrm{AlC}_{2}$ and $\mathrm{Ti}_{2} \mathrm{AlC}$ are two typical materials that have been mostly studied. For example, it is reported that $\mathrm{Ti}_{3} \mathrm{AlC}_{2}$ exhibits room-temperature compressive plasticity in contrast to normal brittle ceramics, and $\mathrm{Ti}_{2} \mathrm{AlC}$ shows excellent machinability. Ti-Al-C ternary compounds can be synthesized by different methods, such as sintering, mechanical alloying, and combustion synthesis.

From the raw materials of $\mathrm{Ti}, \mathrm{Al}$, carbon black, and $\mathrm{TiC}$, both $\mathrm{Ti}_{3} \mathrm{AlC}_{2}$ and $\mathrm{Ti}_{2} \mathrm{AlC}$ can be prepared by combustion synthesis [35-38]. In the synthesized products, $\mathrm{TiC}$ is also present other than the Ti-Al-C ternary compounds, as revealed by XRD patterns shown in Figure 28. In the combustion synthesis of Ti-Al-C ternary carbides, two reaction stages are generally involved:

$$
\begin{gathered}
\mathrm{Ti}+\mathrm{C} \rightarrow \mathrm{TiC} \text { and } \mathrm{Ti}+\mathrm{Al} \rightarrow \mathrm{Ti}-\mathrm{Al} \text { melt } \\
\mathrm{TiC}+\mathrm{Ti}-\mathrm{Al} \text { melt } \rightarrow \mathrm{Ti}_{3} \mathrm{AlC}_{2} / \mathrm{Ti}_{2} \mathrm{AlC}
\end{gathered}
$$

In the formation of $\mathrm{Ti}_{3} \mathrm{AlC}_{2}$ and $\mathrm{Ti}_{2} \mathrm{AlC}$, $\mathrm{TiC}$ is involved as an intermediate product, which is produced first and then reacts with $\mathrm{Ti}-\mathrm{Al}$ melt to form ternary carbides. That is to say, the ternary carbides are produced through a dissolution-precipitation process. Because the combustion reaction occurs quickly, the dissolution of $\mathrm{TiC}$ is often incomplete in a limited period, and some un-reacted $\mathrm{TiC}$ remains in final products.
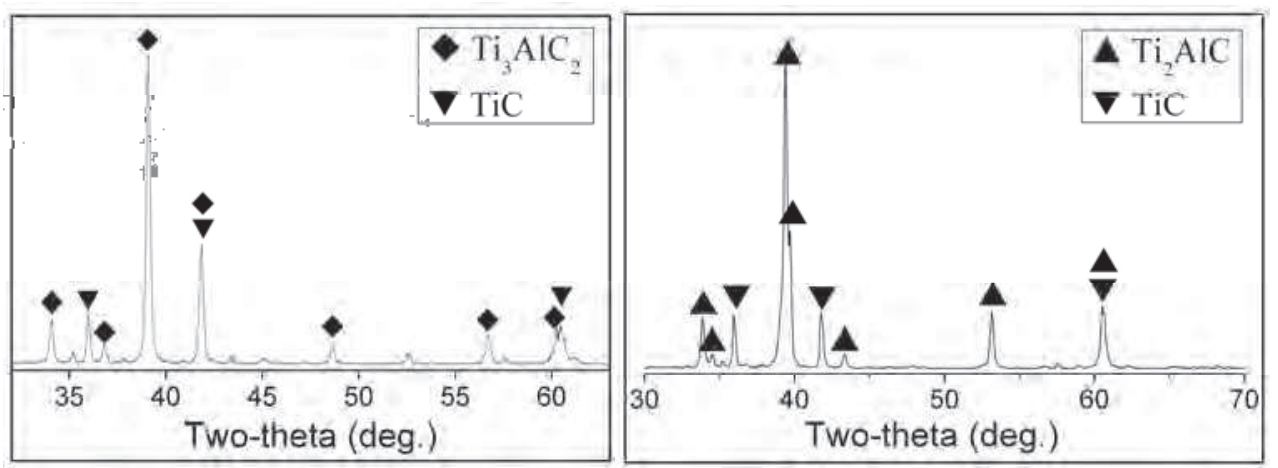

Fig. 28. XRD patterns of $\mathrm{Ti}_{3} \mathrm{AlC}_{2}$ and $\mathrm{Ti}_{2} \mathrm{AlC}$ powders prepared by combustion synthesis

Figure 29 shows the SEM images of $\mathrm{Ti}_{3} \mathrm{AlC}_{2}$ and $\mathrm{Ti}_{2} \mathrm{AlC}$ powders prepared by combustion synthesis, where lamellar grains are observed. More careful observation reveals that most grains exhibit a terraced structure with parallel layers overlapped. This terraced morphology is proposed to be caused by a two-dimensional nucleation and growth mechanism. As illustrated in Figure 30, when a lamellar grain is precipitated from the Ti-Al$\mathrm{C}$ melt and grows larger than a critical size, it can act as a substrate for the nucleation of new grains. The new grains then grow up and form a new layer (the second layer) on the substrate. Similarly, when the second layer become enough large the third layer can form on it. Finally, a terraced structure is produced by continuous stacking of parallel layers. In this process, each layer undergoes a preferential growth, expanding quickly along radial (R) directions in the basal plane but growing slowly in normal $(\mathrm{N})$ direction. 

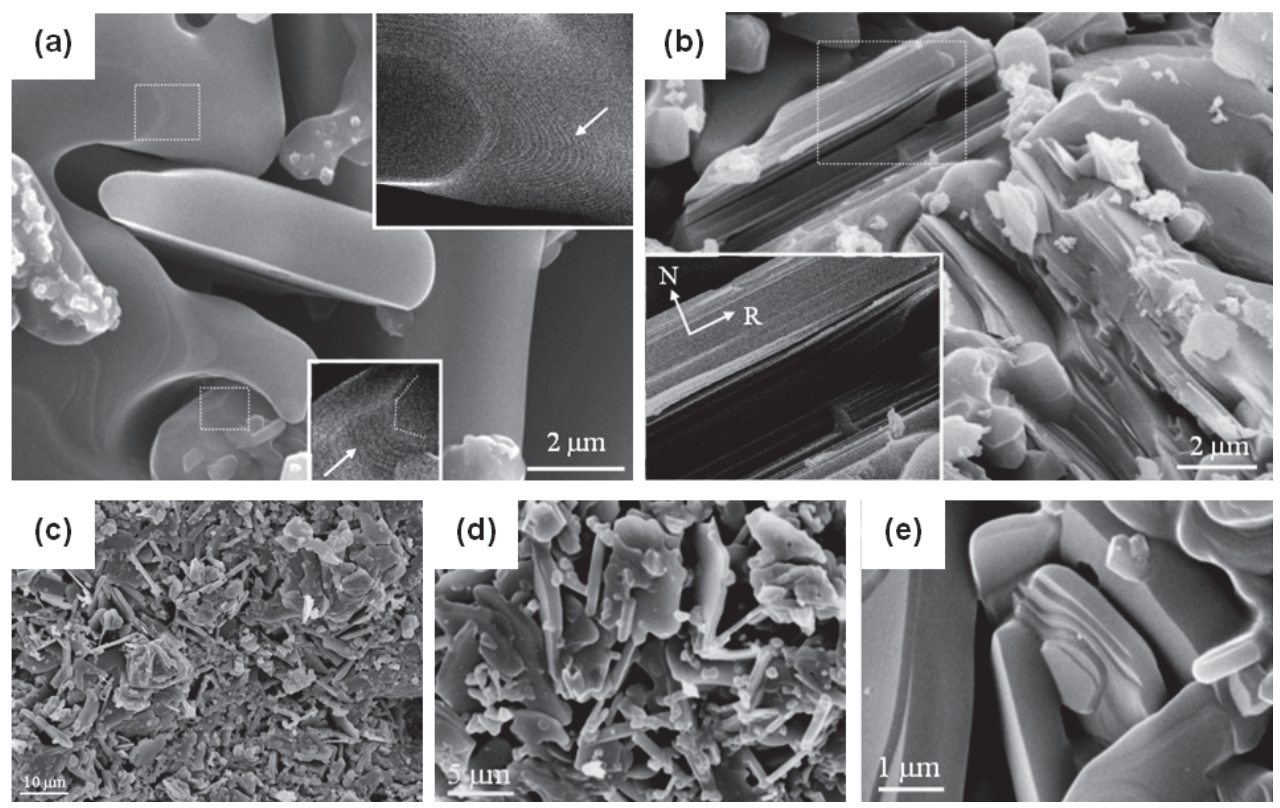

Fig. 29. SEM images of (a) and (b) $\mathrm{Ti}_{3} \mathrm{AlC}_{2}$ and (c)-(e) $\mathrm{Ti}_{2} \mathrm{AlC}$ powders prepared by combustion synthesis

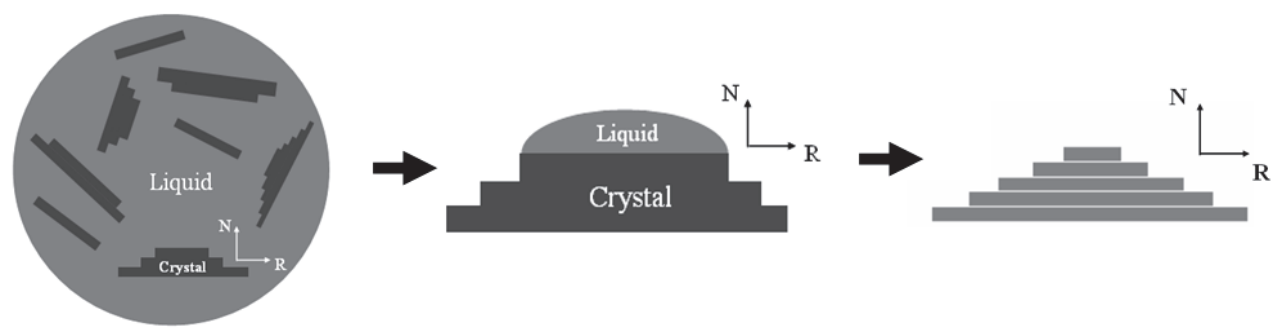

Fig. 30. A schematic illustration of the formation mechanism of the terraced structure in Ti-Al-C ternary carbides prepared by combustion synthesis

Based on the two-dimensional nucleation and growth mechanism, the phase formation and microstructure evolution can be further discussed in detail. At first, $\mathrm{Ti}_{3} \mathrm{AlC}_{2}$ and $\mathrm{Ti}_{2} \mathrm{AlC}$ grains are precipitated from the Ti-Al-C liquid matrix. The ternary carbide grains are separately distributed in a continuous liquid and each grain is surrounded by liquid. At this stage, the material supply for the growth of the lamellar layers is sufficient. With the formation and growth of more ternary carbide grains, the volume proportion of liquid greatly decreases. The ternary carbides become the major phase, and the liquid is not continuous but separately located at the surface of the ternary carbide grains. In this case, the nucleation and growth of new layers take place at the interface between the liquid and the ternary carbide crystals, and the growth of the underlying layers with no contact with liquid is not active. Finally, the liquid phase disappears by severe consumption and with the 
decrease in temperature, and the growth of the ternary carbide crystals stops, leaving a terraced structure .

Figure 31 shows TEM images and SAED patterns of $\mathrm{Ti}_{2} \mathrm{AlC}$ and $\mathrm{Ti}_{3} \mathrm{AlC}_{2}$ lamellar crystals prepared by combustion synthesis. For both $\mathrm{Ti}_{2} \mathrm{AlC}$ and $\mathrm{Ti}_{3} \mathrm{AlC}_{2}$, the basal faces of the lamellar crystals are parallel to (001) plane and the normal direction is parallel to the c-axis in the hexagonal lattice. Similar result has been found in $\mathrm{Ti}_{3} \mathrm{SiC}_{2}$, which is another typical ternary carbide with the same hexagonal structure as $\mathrm{Ti}_{3} \mathrm{AlC}_{2}$. It is reported that, the linking modes of octahedral $\mathrm{Ti}_{6} \mathrm{C}$ units have a strong influence on the growth behavior and morphology of $\mathrm{Ti}_{3} \mathrm{SiC}_{2}$ grains [39]. In the direction along c-axis, the $\mathrm{Ti}_{6} \mathrm{C}$ octahedrons are separated by $\mathrm{Si}$ atomic layers, and hence the growth rate is much lower that those in other directions. Therefore, the ideal crystal morphology of $\mathrm{Ti}_{3} \mathrm{SiC}_{2}$ should be a hexagonal prism bounded with $\{110\}$ and $\{001\}$ faces. The above analysis on the growth kinetics of $\mathrm{Ti}_{3} \mathrm{SiC}_{2}$ is also applicable to $\mathrm{Ti}_{3} \mathrm{AlC}_{2}$ and $\mathrm{Ti}_{2} \mathrm{AlC}$. That is to say, during the growth of $\mathrm{Ti}_{3} \mathrm{AlC}_{2}$ and $\mathrm{Ti}_{2} \mathrm{AlC}$ lamellar crystals, the growth rate in the direction parallel to c-axis should be lower than those in other directions. In this case, the (001) faces will be exposed most frequently in final crystal shape, resulting in a lamellar morphology.
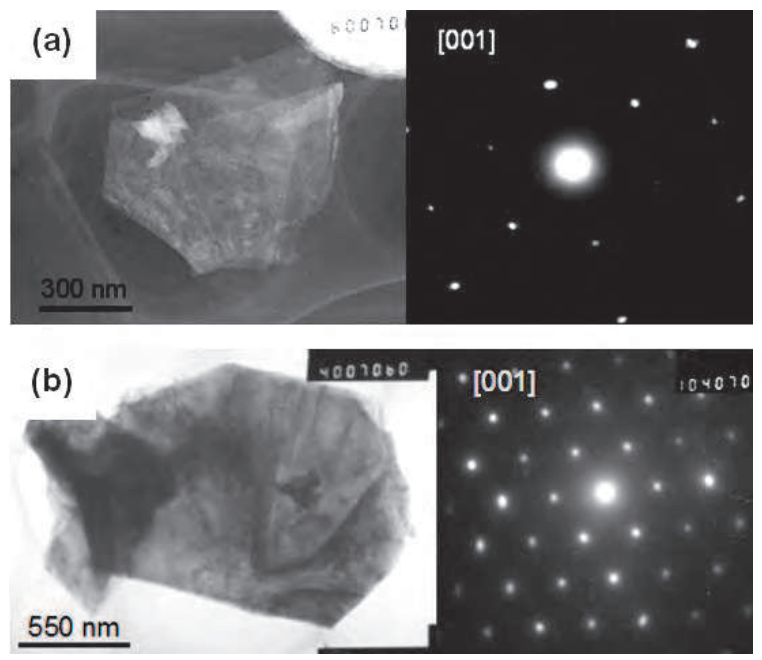

Fig. 31. TEM images and SAED patterns of (a) $\mathrm{Ti}_{2} \mathrm{AlC}$ and (b) $\mathrm{Ti}_{3} \mathrm{AlC}_{2}$ lamellar crystals

\section{Conclusions and perspectives}

With the progress of theories and development of experimental skills, combustion synthesis has shown an increasing importance in preparing ceramic materials. The unique nonequilibrium reaction state in combustion synthesis offers an opportunity to control crystal growth kinetics. By combustion synthesis, ceramics powders with various grain morphologies can be prepared, including faceted, rod-like, and lamellar crystals. This advantage of combustion synthesis is desirable for both basic research on crystal growth and industrial applications of ceramic powders.

Besides the results presented in this chapter, other new findings have been recently reported related with combustion synthesis of ceramic materials. For example, some nitride ceramic 
powders were prepared by combustion synthesis in air instead of high-pressure $\mathrm{N}_{2}$ atmosphere [40-44]. This enhances the advantage of combustion synthesis as a low-cost technique and shows the possibility to further reduce the production cost of nitride powders. In addition, combustion synthesis was carried out in a high-gravity field to directly fabricate bulk ceramics through melt-casting. By this method, both single-phase translucent ceramics and eutectic ceramic composites have been prepared [45-48]. These new findings expand the field for the application of combustion synthesis and make this versatile technique available for preparing more kinds of ceramic materials.

\section{Acknowledgements}

This work was supported by National Natural Science Foundation of China (Grant No. 50102002, 50932006, and 51002163).

The first author would like to thank Prof. Zhou Heping, Dr. Ge Zhenbin, and Prof. Guo Junming for their great help and instructive discussions.

\section{References}

[1] Munir Z A, Umberto A T. Mater Sci Rep, 1989, 3:277.

[2] Merzhanov A G. Ceram Int, 1995, 21:371.

[3] Moore J J, Feng H J. Prog Mater Sci, 1995, 39:243.

[4] Moore J J, Feng H J. Prog Mater Sci, 1995, 39:275.

[5] Toth L E. Transition metal carbides and nitrides, Academic Press, New York, 1971.

[6] Liu G H, Chen K X, Zhou H P, Tian J J, Pereira C, Ferreira J M F. Cryst Growth Des, 2006, 6:2404.

[7] Pamplin B R. Crystal growth, Pergamon Press Ltd., U. K., 1980.

[8] Hartman P. Crystal growth: an introduction, North-Holland Publishing Company, The Netherlands, 1973.

[9] Padture N P, Lawn B R. J Am Ceram Soc, 1994, 77:2518.

[10] She J H, Jiang D L. Ceram Eng, 1998, 227:3.

[11] Nagano T, Kaneko K, Zhan G D, Mitomo M. J Am Ceram Soc, 2000, 83:2497.

[12] Peng H, Salamon D, Bill J, Rixecher G, Burghard Z, Aldinger F, Shen Z J. Adv Eng Mater, 2007, 9:303.

[13] Liu G H, Yang K, Li J T, Du J S, Hou X Y. J Phys Chem C, 2008, 112:6285.

[14] Pampuch R, Stobierski L, Lis J, Rczka M. Mater Res Bull, 1987, 22:1225.

[15] Gorovenko V I, Knyazik V A, Shteinberg A S. Ceram Int, 1993, 19:129.

[16] Narayan J, Raghunathan R, Chowdhurry R, Jagannadham K. J Appl Phys, 1994, 75:7252.

[17] Jack K H. J Mater Sci, 1976, 11:1135.

[18] Ekstrom T, Nygren M. J Am Ceram Soc, 1992, 75:259.

[19] Chen I W, Rosenflanz A. Nature, 1997, 389:701.

[20] Shen Z J, Zhao Z, Peng H, Nygren M. Nature, 2002, 417:266.

[21] Liu G H, Chen K X, Zhou H P, Ferreira J. J Mater Res, 2004, 19:3408.

[22] Liu G H, Chen K X, Zhou H P, Ning X S, Ferreira J. J Eur Ceram Soc, 2005, 25:3361.

[23] Liu G H, Chen K X, Zhou H P, Pereira C, Ferreira J. J Am Ceram Soc, 2006, 89:364.

[24] Liu G H, Chen K X, Zhou H P, Ren K G, Li J T, Pereira C, Ferreira J. Scripta Mater, 2006, 55:935. 
[25] Liu G H, Pereira C, Chen K X, Zhou H P, Ning X S, Ferreira J. J Alloy Comp, 2008, 454:476.

[26] N Shibata, S Pennycook, T Gosnell, G Painter, W Shelton, P Becher. Nature, 2004, 428:730.

[27] A Ziegler, J Idrobo, M Cinibulk, C Kisielowski, N Browning, R Ritchie1. Science, 2004, 306:1768.

[28] M Kramer, M Hoffman, G Petzow. J Am Ceram Soc, 1993, 76: 2778.

[29] M Kitayama, K Hirao, M Toriyama, S Kanzaki. Acta Mater, 1998, 46:6541.

[30] I W Chen, A Davenport, L Wang. Acta Mater, 2003, 51:1691.

[31] M Kramer, D Wittmuss, H Kuppers, M Hoffmann, G Petzow. J Cryst Growth, 1994, 140:157.

[32] M Barsoum, T Elraghy. J Am Ceram Soc, 1996, 79:1953.

[33] M Barsoum, D Brodkin, T Elraghy. Scr Metall Mater, 1997, 36:535.

[34] Y C Zhou, Z M Sun. Phys Rev B, 2000, 61:12570.

[35] W C Lee, S L Chung. J Am Ceram Soc, 1997, 80:53.

[36] A G Zhou, C A Wang, Y Huang. Mater Sci Eng A, 2003, 352:333.

[37] Z B Ge, K X Chen, J M Guo, H P Zhou, J Ferreira. J Eur Ceram Soc, 2003, 23:567.

[38] Liu G H, Chen K X, Zhou H P, Guo J M, Ren K G, Ferreira J. Mater Lett, 2007, 61:779.

[39] K Tang, C Wang, Y Huang, Q Zan. J Cryst Growth, 2001, 222:130.

[40] Liu G H, Chen K X, Zhou H P, Ren K G, Jin H B, Ferreira J. J Am Ceram Soc, 2007, 90:2918.

[41] Liu G H, Chen K X, Zhou H P, Li J T, Pereira C, Ferreira J. Mater Res Bull, 2007, 42:989.

[42] Li J T, Mei L, Yang Y, Lin Z M. J Am Ceram Soc, 2009, 92:636.

[43] Mei L, Li J T. Acta Mater, 2008, 56:3543.

[44] Yang Y, Lin Z M, Li J T. J Eur Ceram Soc, 2009, 29:175.

[45] Z Zhao, L Zhang, Y Song, W Wang. Scripta Mater, 2008, 58:207.

[46] R Liang, J Pei, J T Li, K X Chen. J Am Ceram Soc, 2009, 92:549.

[47] J Pei, J T Li, G H Liu, K X Chen. J Alloy Comp, 2009, 476:854.

[48] L Mei, P Mai, J T Li, K X Chen. Mater Lett, 2010, 64:68. 


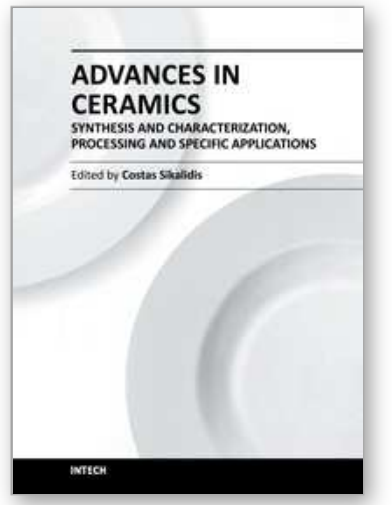

\author{
Advances in Ceramics - Synthesis and Characterization, \\ Processing and Specific Applications \\ Edited by Prof. Costas Sikalidis
}

ISBN 978-953-307-505-1

Hard cover, 520 pages

Publisher InTech

Published online 09, August, 2011

Published in print edition August, 2011

The current book contains twenty-two chapters and is divided into three sections. Section I consists of nine chapters which discuss synthesis through innovative as well as modified conventional techniques of certain advanced ceramics (e.g. target materials, high strength porous ceramics, optical and thermo-luminescent ceramics, ceramic powders and fibers) and their characterization using a combination of well known and advanced techniques. Section II is also composed of nine chapters, which are dealing with the aqueous processing of nitride ceramics, the shape and size optimization of ceramic components through design methodologies and manufacturing technologies, the sinterability and properties of $\mathrm{ZnNb}$ oxide ceramics, the grinding optimization, the redox behaviour of ceria based and related materials, the alloy reinforcement by ceramic particles addition, the sintering study through dihedral surface angle using AFM and the surface modification and properties induced by a laser beam in pressings of ceramic powders. Section III includes four chapters which are dealing with the deposition of ceramic powders for oxide fuel cells preparation, the perovskite type ceramics for solid fuel cells, the ceramics for laser applications and fabrication and the characterization and modeling of protonic ceramics.

\title{
How to reference
}

In order to correctly reference this scholarly work, feel free to copy and paste the following:

Guanghua Liu, Jiangtao Li and Kexin Chen (2011). Combustion Synthesis of Ceramic Powders with Controlled Grain Morphologies, Advances in Ceramics - Synthesis and Characterization, Processing and Specific Applications, Prof. Costas Sikalidis (Ed.), ISBN: 978-953-307-505-1, InTech, Available from: http://www.intechopen.com/books/advances-in-ceramics-synthesis-and-characterization-processing-andspecific-applications/combustion-synthesis-of-ceramic-powders-with-controlled-grain-morphologies

\section{INTECH}

open science | open minds

\author{
InTech Europe \\ University Campus STeP Ri \\ Slavka Krautzeka 83/A \\ 51000 Rijeka, Croatia \\ Phone: +385 (51) 770447 \\ Fax: +385 (51) 686166 \\ www.intechopen.com
}

\author{
InTech China \\ Unit 405, Office Block, Hotel Equatorial Shanghai \\ No.65, Yan An Road (West), Shanghai, 200040, China \\ 中国上海市延安西路65号上海国际贵都大饭店办公楼 405 单元 \\ Phone: +86-21-62489820 \\ Fax: +86-21-62489821
}


(C) 2011 The Author(s). Licensee IntechOpen. This chapter is distributed under the terms of the Creative Commons Attribution-NonCommercialShareAlike-3.0 License, which permits use, distribution and reproduction for non-commercial purposes, provided the original is properly cited and derivative works building on this content are distributed under the same license. 